DOE/ET/15601_-T71

FE-15601-TR-13

Topical Report 13

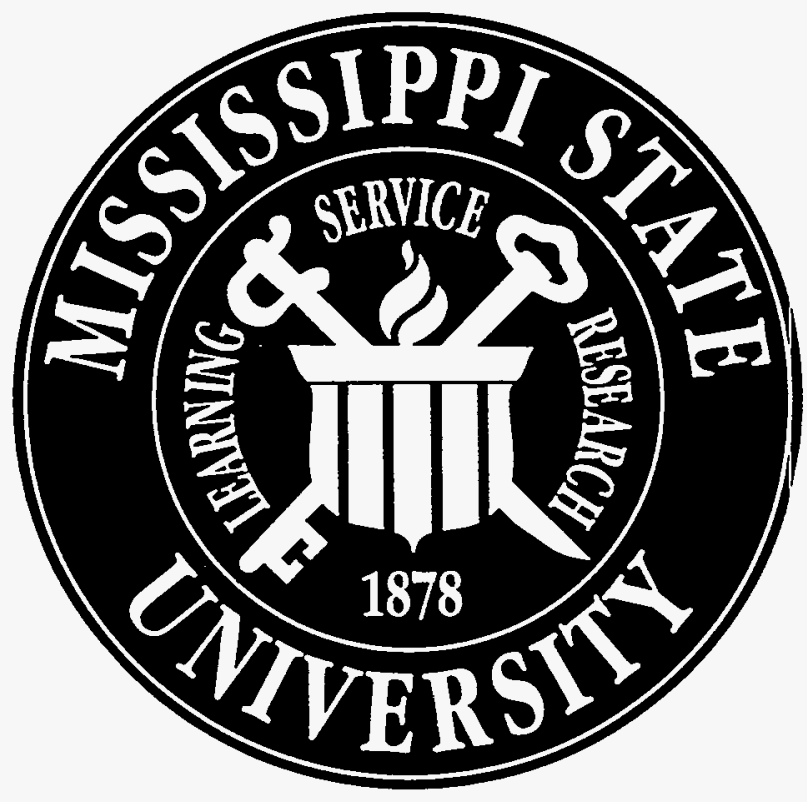

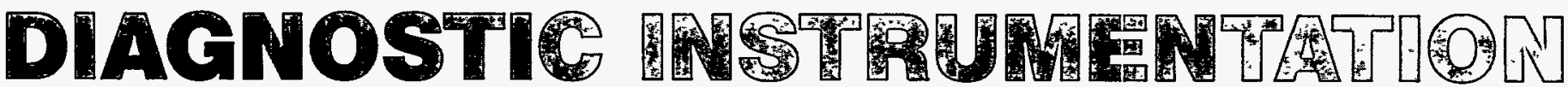 AND ANALYSIS LABORATORI
}

\section{PARTICLE SIZE DISTRIBUTION INSTRUMENT}

\section{TOPICAL REPORT}

Walter Okhuysen and James D. Gassaway

Prepared for the United States

Department of Energy

Under Contract No. DE-AC02-80ET-15601 


\section{DISCLAIMER}

Portions of this document may be illegible in electronic image products. Images are produced from the best available original document. 
FE-15601

Topical Report 13

\title{
PARTICLE SIZE DISTRIBUTION INSTRUMENT
}

\author{
Topical Report
}

Walter Okhuysen and James D. Gassaway
Diagnostic Instrumentation and Analysis Laboratory Mississippi State University

\section{DISCLAIMER}

This report was prepared as an account of work sponsored by an agency of the United States Government. Neither the United States Government nor any agency thercof, nor any of their employees, makes any warranty, express or implied, or assumes any legal liability or responsibility for the accuracy, completeness, or usefulness of any information, apparatus, product, or process disclosed, or represents that its use would not infringe privately owned rights. Reference herein to any specific commercial product, process, or service by trade name, trademark, manufacturer, or otherwise does not necessarily constitute or imply its endorsement, recommendation, or favoring by the United States Government or any agency thereof. The views and opinions of authors expressed herein do not necessarily state or reflect those of the United States Government or any agency thereof.

Prepared for U.S. Department of Energy

Contract No. DE-AC02-80ET-15601 
This report was prepared as an account of work sponsored by the United States Government. Neither the United States nor the United States Department of Energy, nor any of their employees, makes any warranty, expressed or implied, or assumes any legal liability or responsibility for the accuracy, completeness, or usefulness of any information, apparatus, product, or process disclosed, or represents that its use would not infringe privately owned rights. Reference herein to any specific commercial product, process, or service by trade name, mark, manufacturer, or otherwise, does not necessarily constitute or imply its endorsement, recommendation, or favoring by the United States Government or any agency thereof. The views and opinions of authors expressed herein do not necessarily state or reflect those of the United States Government or any agency thereof. 


\section{TABLE OF CONTENTS}

LIST OF FIGURES $\ldots \ldots \ldots \ldots \ldots \ldots \ldots \ldots \ldots \ldots \ldots \ldots \ldots \ldots \ldots \ldots \ldots \ldots \ldots$

LIST OF TABLES $\ldots \ldots \ldots \ldots \ldots \ldots \ldots \ldots \ldots \ldots \ldots \ldots \ldots \ldots \ldots \ldots \ldots, \mathrm{v}$

LIST OF APPENDICES $\ldots \ldots \ldots \ldots \ldots \ldots \ldots \ldots \ldots \ldots \ldots \ldots \ldots \ldots \ldots \ldots \ldots$

NOMENCLATURE $\ldots \ldots \ldots \ldots \ldots \ldots \ldots \ldots \ldots \ldots \ldots \ldots \ldots \ldots \ldots \ldots$ vii

ABSTRACT $\ldots \ldots \ldots \ldots \ldots \ldots \ldots \ldots \ldots \ldots \ldots \ldots \ldots \ldots \ldots \ldots \ldots \ldots \ldots \ldots$

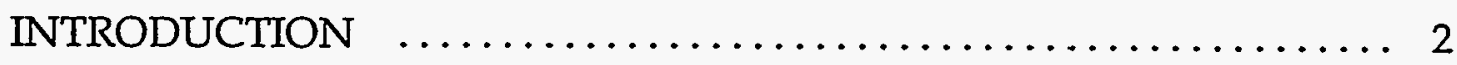

PURPOSE AND NEED $\ldots \ldots \ldots \ldots \ldots \ldots \ldots \ldots \ldots \ldots \ldots \ldots \ldots$

MEASUREMENT OBJECTIVES, CONDITION

AND CONSTRAINTS $\ldots \ldots \ldots \ldots \ldots \ldots \ldots \ldots \ldots \ldots \ldots, 6$

TECHNICAL APPROACH $\ldots \ldots \ldots \ldots \ldots \ldots \ldots \ldots \ldots \ldots \ldots$

SYSTEM DESCRIPTION $\ldots \ldots \ldots \ldots \ldots \ldots \ldots \ldots \ldots \ldots \ldots \ldots, 20$

INSTRUMENT MODIFICATIONS FOR FIELD MEASUREMENTS $\ldots . \quad 38$

CURRENT STATUS $\ldots \ldots \ldots \ldots \ldots \ldots \ldots \ldots \ldots \ldots \ldots \ldots \ldots, 44$

ACKNOWLEDGMENTS $\ldots \ldots \ldots \ldots \ldots \ldots \ldots \ldots \ldots \ldots \ldots \ldots, 46$

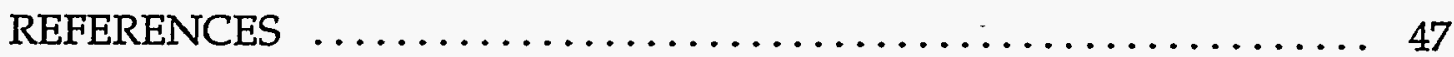

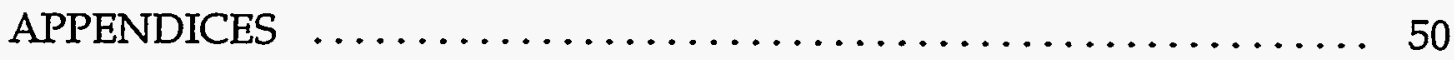

15601-TR-13-PSD-6-94 


\section{LIST OF FIGURES}

Figure 1. Polar diagram of Mie scattering response for a particle . . . . 17

Figure 2. SANFS signal relationship $\ldots \ldots \ldots \ldots \ldots \ldots \ldots \ldots \ldots \ldots$

Figure 3. Visibility signal relationship $\ldots \ldots \ldots \ldots \ldots \ldots \ldots \ldots$

Figure 4 . Block diagram of PSD instrument $\ldots \ldots \ldots \ldots \ldots \ldots \ldots, 32$

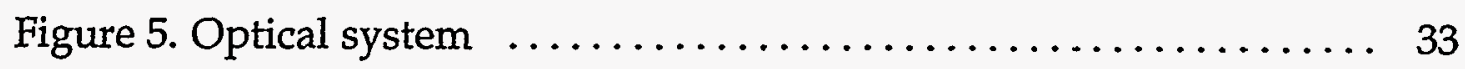

Figure 6. Transmission optics $\ldots \ldots \ldots \ldots \ldots \ldots \ldots \ldots \ldots \ldots \ldots \ldots \ldots$

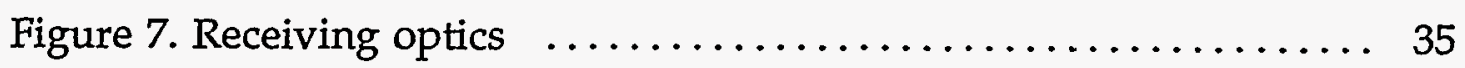

Figure 8. Photomultiplier tube gain vs. photocathode high voltage $\ldots 36$

Figure 9. Block diagram for PSD signal processor $\ldots \ldots \ldots \ldots \ldots \ldots 37$

15601-TR-13-PSD-6-94 iv 
LIST OF TABLES

Table I. Flow Conditions $\ldots \ldots \ldots \ldots \ldots \ldots \ldots \ldots \ldots \ldots$

Table II. Flow Channel Environment $\ldots \ldots \ldots \ldots \ldots \ldots \ldots \ldots \ldots$

Table III. Photomultiplier Tube Specifications $\ldots \ldots \ldots \ldots \ldots \ldots .25$

Table IV. Scattered Light Receiver Parameters $\ldots \ldots \ldots \ldots \ldots \ldots .26$ 


\section{LIST OF APPENDICES}

APPENDIX A. PSD Measurement at CFFF ESP Exit Duct: Coal

Combustion and No $K_{2}$ Seed Injection, ESP Flow @ 6000 cfm ... 51

APPENDIX B. PSD Measurement at CFFF ESP Exit Duct: Coal

Combustion and Step $6 \mathrm{~K}_{2}$ Seed Injection, ESP Flow @ $9000 \mathrm{cfm}$. 55

APPENDIX C. PSD Measurement at CFFF ESP Exit Duct: Coal

Combustion and Step $8 \mathrm{~K}_{2}$ Seed Injection, ESP Flow @ $9000 \mathrm{cfm}$. 59

APPENDIX D. Plot of PSD at UTSI CFFF ESP Exit Duct $\ldots \ldots \ldots \ldots \ldots 63$ 


\section{NOMENCLATURE}

\begin{tabular}{|c|c|}
\hline $\mathrm{AC}$ & Alternating current \\
\hline A/D & Analog to digital convertor \\
\hline$A_{R^{\prime}}$ & Effective collecting aperture area of scattered light receiver \\
\hline CFFF & Coal-Fired Flow Facility at UTSI \\
\hline $\mathrm{cm}$ & Centimeter \\
\hline $\mathrm{d}$ & Particle diameter \\
\hline$d B$ & Decibel \\
\hline DIAL & Diagnostic Instrumentation and Analysis Laboratory at MSU \\
\hline DC & Direct current \\
\hline DOE & Department of Energy \\
\hline e & Base for Napierian logarithms \\
\hline es & Pulse amplitude \\
\hline FL & Focal length of a lens or mirror \\
\hline FOV & Field of view for an optical receiver \\
\hline $\mathrm{f}_{\mathrm{R}}$ & Focal length of the receiving lens \\
\hline $\mathrm{f}_{\mathrm{T}}$ & Focal length of the transmitting lens \\
\hline FV & Forward visibility \\
\hline FWHM & Full width at half maximum \\
\hline $\mathrm{GPMT}_{\mathrm{P}}$ & Photomultiplier sensitivity \\
\hline $\mathrm{G}_{\mathrm{T}}$ & Transconductance gain of an amplifier \\
\hline HRSR & Heat Recovery/Seed Recovery \\
\hline I & Intensity of optical beam \\
\hline$I^{\prime}$ & Focused intensity of laser beam \\
\hline $\mathrm{k}$ & Wavevector for electro-magnetic wave \\
\hline$\lambda$ & Wavelength \\
\hline LDV & Laser doppler velocimeter \\
\hline $\log$ & Logarithm \\
\hline MHD & Magnetohydrodynamics \\
\hline $\mathrm{MHz}$ & Frequency in millions of cycles per second \\
\hline MSU & Mississippi State University \\
\hline $\mathrm{N}$ & Number density in number of particles per cubic centimeter \\
\hline 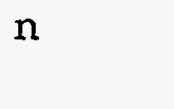 & $\begin{array}{l}\text { Number of particles present in sample volume or index of } \\
\text { refraction }\end{array}$ \\
\hline & Nanometer \\
\hline & Nanosecond \\
\hline micron & Micrometer \\
\hline $\mathrm{mi}$ & Thousandths of an inch \\
\hline
\end{tabular}




$\begin{array}{ll}\mu \mathrm{m} & \text { Micrometer } \\ \mathrm{m} \mathrm{m} & \text { Millimeter } \\ \mathrm{m} W & \text { MilliWatt } \\ \omega & \text { Laser beam radius } \\ \omega^{\prime} & \text { Focused laser beam radius } \\ \mathrm{P} & \text { Probability of occurrence of an event } \\ \mathrm{P} & \text { Power of laser beam } \\ \pi & \text { Circumference of a circle divided by its diameter } \\ \mathrm{P}_{\mathrm{i}} & \text { Probability of two or more interfering particles in sample } \\ & \quad \text { volume } \\ \text { PMT } & \text { Photomultiplier tube optical transducer } \\ \mathrm{PSD} & \text { Particle size distribution } \\ \mathrm{RDM} & \text { Ripple deconvolution method } \\ \mathrm{RVS} & \text { Ripple validated small angle near-forward scattering } \\ \mathrm{S}-100 & \text { Micro computer bus standard } \\ \mathrm{SANFS} & \text { Small angle near forward scattered } \\ \text { SR } & \text { Normalized SANFS response } \\ \mathrm{UTSI} & \text { University of Tennessee Space Institute, Tullahoma, TN } \\ \mathrm{V}_{\mathrm{S}} & \text { Sample volume } \\ \Omega & \text { Electrical impedance in ohms }\end{array}$




\begin{abstract}
The development of an instrument to measure the concentration of particles in gas is described in this report. An in situ instrument was designed and constructed which sizes individual particles and counts the number of occurrences for several size classes. Although this instrument was designed to detect the size distribution of slag and seed particles generated at an experimental coal-fired magnetohydrodynamic power facility, it can be used as a nonintrusive diagnostic tool for other hostile industrial processes involving the formation and growth of particulates. Two of the techniques developed are extensions of the widely used crossed beam velocimeter, providing simultaneous measurement of the size distribution and velocity of particles.
\end{abstract}




\section{INTRODUCTION}

This report describes the design and development of an optical instrument to measure the size distribution of particles entrained in a gas flow stream. The work was done by the Diagnostic Instrumentation and Analysis Laboratory (DIAL) at Mississippi State University (MSU) with funding provided by the U.S. Department of Energy (DOE) under Contract DE-AC02-80ET-15601. The motivation for developing this instrument was to support activities of the U.S. DOE's coal-fired magnetohydrodynamics (MHD) proof-of-concept program and to determine the efficacy of components developed for DOE's Heat Recovery/Seed Recovery (HRSR) program. 


\section{PURPOSE AND NEED}

Power generation by the magnetohydrodynamic (MHD) process is under investigation as method of converting coal fossil fuel resources to electricity with a potential increase in electric power generation efficiencies of up to $50 \%$ compared to conventional coal-burning power plants. This is achieved by burning coal to produce an electrically conducting plasma which is passed through a magnetic field. The electric current induced in the flowing plasma by the Faraday effect is extracted with electrodes embedded in the containment channel. Since no moving parts are required, the thermodynamic cycle can operate at a higher temperature and thus higher efficiency. The MHD power generating channel is known as the topping cycle because higher temperatures are utilized. A bottoming cycle utilizes the thermal energy remaining in the hot combustion gases exiting the MHD channel to generate more electricity. A conventional Rankine cycle using radiant boilers to generate the steam for the bottoming cycle turbines is under consideration.

The gas stream of a coal-fired MHD generator must be seeded with an easily ionizable material (potassium salt) to obtain a plasma with electrical conductivity sufficient to produce electric current. The seed along with other noncombustibles (slag) are transported through the components of the combined cycle MHD power plant. The seed and slag, which may be present as vapor in the higher temperature regions of the flow train, condense to form particles as the gas stream is cooled. This nucleation and growth process must be understood so bottoming cycle components can be designed to prevent detrimental fouling by particles. In addition, the economic and environmental feasibility of the MHD generator concept depends on the ability to separate particulate matter from the gaseous products of combustion. The collected slag/seed is then separated with a seed regeneration process with the seed reused and the ash material disposed.

Particulate concentration measurements will allow potential problem areas to be identified, and different methods can be implemented and tested in the pilot scale studies of the heat recovery/seed recovery (HRSR) program. In particular, concentration measurements at various locations along the flow stream will allow designers to identify and quantify ash/seed nucleation, growth, and deposition rates. Bottoming cycle components for a commercial MHD power plant can then be 
designed utilizing the techniques developed during the proof-of-concept program.

\section{Existing Technology}

The measurement of particulate emissions from power generating plants and industrial processes is predominantly accomplished by extracting samples from the stack or process stream. Two methods which are commonly used are a total mass sample extraction and a size distribution measurement with an inertial separation probe assembly. Both of these use an isokinetic probe to extract a sample from the flow stream without slowing the particles. This is necessary to collect a sample representative of the flow since otherwise the aerodynamic characteristics of a sampling probe tip would bias the size distribution of the sample.

A total mass sample is collected by sucking the particulate laden gas through a filter substrate. The filter is placed in a holder that is close to the probe's extraction nozzle tip and the holder is commonly inserted into the larger flow channels (with diameter larger than 0.3 meter). The probe is then extracted from the flow channel and the sample which was collected on the filter is weighed. The inertial separation methods utilize either a cascade of centrifuge cyclones or impactor plates and orifices. Cascades of cyclones typically classify the particles into six ranges. The cut points of the Southern Research Institute's five-stage design are $0.3,0.5,1,3$ and 5 microns. 1 The cut points for Anderson's Mark IV nine-stage in-stack cascade impactor are given as $0.41,0.74,1.2,1.8,3.0,4.7,7.5$ and 11.4.2

Once a particulate sample is collected, several methods are available for determining the size of the particles. Optical and scanning electron microscopes can be used to generate micrographs from which particles in different size classes are counted. Various optical light scattering instruments can also be used to analyze samples of particulate laden gas. Electrical mobility analyzers which can size submicron particles are also available. Several individuals 3,4 have developed optical instruments for determination of particle size and/or concentration, but these are limited to laboratory use and are not commercially available.

\section{Limitations of Current Methods}

Most of these instruments do not give concentration measurements directly, and the conditions under which the sample is extracted deter- 
mine if the inevitable size bias can be overcome. The intrusive nature of the sample extraction process presents additional problems in high temperature or highly corrosive environments. Methods which rely heavily on sample extraction also preclude the possibility of obtaining real time measurements. A typical turn-around cycle for recovering a sample from an inertial separation probe is on the order of hours. Among the other problems frequently encountered are:

(1) the long sample times required to collect enough mass in the smallest size class stages;

(2) the difficulty of maintaining isokinetic sampling conditions when the flow rate changes due to process perturbations which cannot be eliminated; and,

(3) the amount of labor required to continuously sample which makes measurements very expensive. 


\section{MEASUREMENT OBJECTIVES, CONDITIONS AND CONSTRAINTS}

The design of an instrument to measure size distribution of particles must be preceded by establishing the objectives of the measurements which are to be performed, and the conditions and constraints under which the instrument will be operated. The primary application for this instrument is to measure the particle size distributions in DIAL's combustion test channel. Other applications include processes at DOE's Heat Recovery/Seed Recovery facility at the University of Tennessee Space Institute (UTSI). This is a pilot scale facility for testing and proving various MHD related processes and components prior to the design and construction of a commercial MHD power generator. Conditions for these additional applications are similar to those for the DIAL combustion test stand except for channel size and particle velocity.

The primary measurement objective is the classification of particle concentration by particle diameter. A further requirement was that the measurement be performed in a nonintrusive manner. Approximate ranges for particle size, total particle number density and particle velocity are listed in Table I.

Table I. Flow Conditions.

\begin{tabular}{||c|c|c||}
\hline PARAMETER & DIAL TEST STAND & CFFF \\
\hline Particle Diameter & $0.5-20 \mathrm{~mm}$ & $0.5-20 \mathrm{~mm}$ \\
\hline Total Number Density & $10^{3}-10^{6} \# / \mathrm{cm}^{3}$ & $10^{3}-106 \# / \mathrm{cm}^{3}$ \\
\hline Flow/Particle Velocity & $5-15 \mathrm{~m} / \mathrm{s}$ & $0.5-100 \mathrm{~m} / \mathrm{s}$ \\
\hline $\begin{array}{c}\text { Channel Size } \\
\text { (including optical } \\
\text { access windows) }\end{array}$ & $0.5 \mathrm{~m}$ & $1-2 \mathrm{~m}$ \\
\hline
\end{tabular}

The primary constraints on the instrument design are largely dictated by the conditions in and surrounding the test channel. The test channel is assumed to be oriented such that the flow is horizontal. Optical access to the gas stream is provided through windows on opposite sides of the test channel. The instrument must operate in an industrial environment consisting of a flow channel exposed to ambient outdoor conditions and a control room with controlled temperature and humidity. Optical assem- 
blies for transmitting the probe beams and receiving the scattered light signals are to be located on each side of the channel with a connecting support structure under the flow channel. The instrument electronics and data acquisition/analysis computer may be located in an environmentally controlled room. Interconnecting cables for instrument control and instrument signals must be designed to be routed through areas containing electrical machinery capable of generating large electric and magnetic fields (large electric motors, high voltage transformers, electrostatic precipitator equipment, etc. ) Table II lists some of the pertinent conditions the instrument should accommodate.

Table II. Flow Channel Environment.

\begin{tabular}{||c|c|c||}
\hline PARAMETERS & DIAL TEST STAND & CFFF \\
\hline Ambient Temperature & $10-40^{\circ} \mathrm{C}$ & $0-40^{\circ} \mathrm{C}$ \\
\hline Exposure to Weather & Indoors & $\begin{array}{c}\text { Under Metal } \\
\text { Shed Roof }\end{array}$ \\
\hline Vibration & Small & Moderate \\
\hline $\begin{array}{c}\text { Supporting Floor } \\
\text { or Platform }\end{array}$ & Concrete & $\begin{array}{c}\text { Steel Grating } \\
\text { Supported by Steel } \\
\text { Beam Framework }\end{array}$ \\
\hline $\begin{array}{c}\text { Space Available for } \\
\text { Instrument Mounting } \\
\text { (each side of channel) }\end{array}$ & $\begin{array}{c}72^{\prime \prime} / 72^{\prime \prime} \\
\text { (from channel } \\
\text { centerline) }\end{array}$ & $\begin{array}{c}72^{\prime \prime} / 60^{\prime \prime} \\
\text { (from channel } \\
\text { centerline) }\end{array}$ \\
\hline $\begin{array}{c}\text { Ambient Light } \\
\text { Conditions }\end{array}$ & $\begin{array}{c}\text { Artificial } \\
\text { (incandescent and } \\
\text { fluorescent) }\end{array}$ & $\begin{array}{c}\text { Day (direct and } \\
\text { diffused sunlight) } \\
\text { Night (artificial } \\
\text { incandescent and } \\
\text { vapor discharge) }\end{array}$ \\
\hline
\end{tabular}

\section{On-line Analysis and Display of Measurement Information}

An additional benefit provided by optical particle size measurement methods is the possibility of near real time response. Since a sample of particle does not have to be extracted and later analyzed by a separate instrument, in situ optical methods eliminate the time delay associated with sample collection, preparation, and tracking. With a single particle counting instrument the sizing and sampling are inherent in the accu- 
mulation of a count histogram and only a simply calculation is necessary to properly weight the counts in the separate size classes. Particle number concentration information can be presented in a graphical format with the temporal variation in a process emphasized by plotting successive concentration histograms with a vertical and horizontal offset to give a three dimensional presentation of the measurement history. 


\section{TECHNICAL APPROACH}

\section{Concepts of Optical Particle Size/Concentration Measturements}

. The basic concept is to delineate a representative volume within the particulate laden fluid, optically determine the size of each individual particle, and then count the number of particles in each size class. The resulting distribution is a measurement of the concentration of particles in each size class since by design the sample contains all particles within the delineated volume. Optical methods differ from conventional sampling methods in the approach used to define the sample of particles within the suspending fluid. Windows are placed on opposing sides of the flow channel and a beam of light (laser beam) is projected across the flow. The sample volume is defined by the laser beam and suitable light collection optics. As individual particles pass through the beam they scatter light forming flashes of light whose intensity is dependent on the particle's diameter. The intensities of these scattered light flashes are measured with a photodetector and the light flashes are classified ancl counted according to their magnitude. Since there exists a relationship between scattered intensity and particle diameter which is determined by the optical and geometrical parameters of the laser beam and scattered light receiver, the size distribution can be determined from the histogram of light flashes.

\section{Sample Volume and Counting}

The formation of the sample volume within the flow channel is fundamental in the determination of the size distribution. Ideally, the sample volume should not bias the counting, but it may not be possible to eliminate all sources of counting bias. Among the variables which may cause incorrect counting of a particle are it's diameter, velocity, residence time, position within the sample volume, etc. The sample volume may be defined optically in the following manner. Consider a beam of light with a circular cross section and uniform intensity. If this ideal beam is projected across a region of fluid containing a particle, the particle will scatter a portion of this light in many directions. Since the particle suspending fluid does not scatter light, the scattered light indicates the presence of the particle and thus the particle is sampled. Similarly a sample volume can be formed by intersecting two coplanar right circular cylinders at an angle. Such a region might be defined by a illumination beam and light collecting optics with a limited field of view (FOV). A particle will be sampled 
only if it is in a region where it is illuminated and thus scatters light and also within the FOV of the light collection optics such that the scattered light can be detected.

If the particles are moving, a sample volume can also be defined by the intersection of illuminated region with the scattered light receiver's FOV, but particles are transported across the sample volume by the flow. The volume of fluid actually sampled depends on the fluid velocity, the dimensions of the sample volume perpendicular to the flow, and the period for which particles are counted. It is necessary that the sample volume be sufficiently small so that the probability of occupancy by multiple particles is small, otherwise multiple particles would be incorrectly sampled as one particle. The probability of occupancy by $n$ particles depends on sample volume, $V_{s}$, and the particle number density, $N$, and is given by the Poisson probability distribution

$$
P\left(n, N, V_{s}\right)=\frac{\exp \left(-N \cdot V_{s}\right) \cdot\left(N \cdot V_{s}\right)^{n}}{n}
$$

The probability of two or more particles occupying the sample volume simultaneously and generating an interference signal is

$$
P_{i}=1-\left[P\left(0, N, V_{s}\right)+P\left(1, N, V_{s}\right)\right]=1-\left[\frac{\left(1+N \cdot V_{s}\right)}{\exp \left(N \cdot V_{s}\right)}\right]
$$

In an actual instrument, $V_{s}$ depends on the particle size thus the probability of interference will be determined by the size distribution of particles. The probability of interference, $P_{i}$, given above is good for estimating the magnitude of $V_{s}$ required for a flow containing $N$ particles per unit volume.

\section{Trajectory Ambiguity Problems}

Typically a laser beam has an intensity profile which has a Gaussian dependence on the distance from the beam centerline, thus the ideal sample volume of uniform illumination is not achievable. This introduces an uncertainty in the determination of size because the scattered pulse amplitude for a particle passing through the sample volume is dependent on the particle's trajectory. This nonuniform intensity prevents the determination of particle size directly from the amplitude of 
scattered light. The limited dynamic range of the optical detector and signal processor will also combine with the trajectory dependence of signal amplitudes to introduce a sampling bias. The generally less prevalent larger particles will be overcounted since a disproportionate number of them will pass through the edges of the sample volume and still be above the detection threshold. Whereas the smaller particles will be detectable in a much smaller volume. The result is that the incorrectly sized larger particles which move through regions of lower intensity will be detected and counted, yet the smaller ones will not.

\section{Determination of Particle Size}

The physics of particle diameter dependence of scattered light has been reviewed by van de Hulst.5-7 Some of the general features of light scattered by particles will be presented. Figure 1 shows the polar diagram for scattered radiation for a single particle with a diameter on the order of a wavelength. Such a diagram can be constructed using the Lorenz-Mie theory which describes the scattering of radiation for a uniformly illuminated sphere.8,9 It should be noted that for this range of particle sizes, the scattering is strongest in the forward direction. The radiation pattern shape and the absolute magnitude of the scattered intensity both depend upon the particle size. Figure 2 shows the scattered intensity dependence upon particle size for two angles of observation with respect to the forward direction. The rippling nature of the response curve and the multilobe nature of the radiation pattern are manifestations of complex EM interferences not predicted by the simpler Fraunhofer approximation theory. For non-absorbing particles the magnitude of these ripples decreases as the scattered light is collected in the region nearer to the forward propagation direction' of the illuminating beam. Thus to achieve an instrument which is insensitive to particle index of refraction (for use when particles have varying or unknown composition), near forward scattered light should be collected. Experimental evidence suggests the Fraunhofer diffraction model which neglects the refractive index is correct to the extent that the near forward scattered amplitude is more dependent upon the particle cross-sectional area than upon the exact shape of the surface.10,11

Figure 2 illustrates two main features. First, there is an upper limit to the particle size which can be determined unambiguously using scattered amplitude measurements. The upper limit depends upon the angle of observation and decreases as that angle increases. Second, there is a rippling nature in the curve that suggests an inevitable limit to the 
resolution which can be achieved. Although these difficulties can be reduced by using a broadband source for illumination, in practice, the optical problems encountered in producing a beam with a diameter suitably small for the application dictate the use of a laser. The waist of the beam after focussing through a transmission lens forms the radial dimension of the probe volume in which the particle is observed. The axial cutoffs of the FOV are determined by masks and pinholes in the receiving optics. Typically, the mask defines the angle of observation, in which case the length of the probe volume decreases as the angle increases. Further considerations warrant a general conclusion that, for a given angle of observation or focused beam diameter, there is a tradeoff between the maximum particle density and the maximum particle diameter which can be analyzed without ambiguity.

Two methods which use the ratio(s) of two (or more) signals to determine size have been intensively investigated. First, there is the multi-ratio forward scatter (MRFS) technique.12,13 This method is based upon the sensitivity of the radiation pattern shape to the particle size and is applicable for particles with diameters larger than approximately one fifth the wavelength. The reduction of the trajectory dependence ambiguity is a complex issue which has been discussed by Hirleman12; however, the field of view for each observation angle must be the same if the sampling bias caused by nonuniform illumination is to be removed. This poses practical difficulties discussed in more detail later.

The visibility ratio methods utilize the ratio of the ripple and pedestal signals generated by the light scattered at the beam crossing of a dual-scatter laser Doppler velocimeter. 14 The peak forward visibility (FV) ratio implementation discussed by Roberds 15,16 does allow reduction of the trajectory dependence ambiguity. However, this peak visibility technique, as well as the average visibility discussed by Farmer 10, has a lower limit for the measurable particle size that is significantly higher than for the MRFS method. Figure 3 shows the flattening of the visibility ratio curve which occurs for small particles. While this response curve calculated using Mie theory shows the limitation, curves calculated using Fraunhofer theory or other simplifications do not. Bachalo17 has given a semi-quantitative discussion of the phenomena. On the other hand, the maximum size of particle which can be measured is not limited but can be increased by reducing the beam crossing angle, with the tradeoff in maximum number density mentioned previously. 


\section{Elimination of Sampling Bias and Size Ambiguity}

Two methods have been proposed to eliminate sampling bias and size ambiguity problems due to trajectory dependent illumination: (1) restrict particle trajectories to an area of uniform illumination; and (2) use an inversion technique to correct for the particle size dependence of the sample volume size. In situ measurements preclude the option of physically restricting trajectories but a uniformly illuminated sample volume can be achieved by counting only the particles that also generate a coincident trajectory validation signal. The region from which the validation signal can be generated may be defined by another illumination beam(s)18-20,21 or by a scattered light receiver(s) with a further restricted field of view(s).22-24

A method has been developed by Holve 25 to determine particle concentration size distribution from unvalidated signals. The sample volume spatial response was mapped out by hand to determine the response of a scattering particle anywhere in the zone where the laser beam and the receiver field of view intersect. The pulse height distribution of all scattered signals from this well characterized sample volume is measured and a mathematical inversion technique is then used to calculate the size distribution required to give the measured pulse height distribution.

Both of these methods have advantages which make the choice of implementation dependent on the application environment. The validation methods are easier to understand but one must realize that the sampling bias is not removed. The origin of the sampling bias is only moved from the sizing illumination beam to the validation beam or field of view. But since the particles are correctly sized, the true size/concentration distribution can be determined from the biased count histogram by weighting the counts of particles in the smaller classes by a factor proportional to the validation detection area. The validation detection area for a particle of diameter, $d$, is the area projected by the validation volume onto a plane perpendicular to the flow vector. The validation volume is the volume through which the particle with diameter, $d$, can pass and still generate a signal larger than the threshold level for validation. The particle size dependence of this validation area can be determined from mapping experiments or from models of the validation region's spatial response. 
Deconvolution methods allow one to use the smallest possible focused beam diameters and one can achieve the smallest possible sample volumes. Thus one can make measurements under high number densities where multiple particles would otherwise be present in the necessarily larger sizing sample volume of a validation technique. There exists the possibility of having an ill-defined inversion problem which has no physically realistic solution, multiple solutions or even no solutions. Holve25-27 has worked extensively on this measurernent technique and has been very successful. Holve's use of a single illumination beam eliminates the need for velocity dependent separation filters and higher bandwidth log amplifiers required by the dual scatter crossed beam laser Doppler velocimeter (LDV) signals. Deconvolution of LDV ripple signals has an advantage in that the sample volume is well defined by the transmitting optics and can be modeled easily. 14 The diameter dependence of this sample volume's detection area is well behaved and a simple inversion matrix can be used to obtain the size/concentration distribution from the unvalidated counts. This advantage is offset by the problems of processing signals of 10 to 20 times greater bandwidth, separating the ripple component from the pedestal component, and intersecting two beams inside the flow channel. The limiting factor for processing signals under high particle density conditions is the short pulse width which decreases linearly with increasing velocity. The shortest pulse width that can be peak detected without using pulse stretching techniques is about 500 nsec. It is this more than the limited bandwidth of logarithmic amplifiers that determines the upper velocity limit for a single particle counting instrument operating under high number density conditions.

\section{Practical Limitations}

Two desirable but conflicting features are: (1) wide measurement range, and (2) small probe volume, hence a capability for analyzing high particle densities. The angle of observation for the measurement would ordinarily be reduced in order to increase the upper limit of size range for unambiguous measurements; however, the range cannot be arbitrarily increased in this manner because of difficulties in stopping the forward beam(s). Furthermore, the length of the probe volume is increased as the observation angle is reduced if the pinhole stop remains fixed in aperture size. The aperture can be reduced in diameter but at the expense of increased difficulty in alignment procedures. Thus, the pinhole aperture cannot be selected solely on the basis of probe volume requirements. 
Although ratio techniques are desirable for the reasons previously mentioned, and also because of insensitivity to changes in instrument parameters due to drift such as photomutiplier tube gain, it is inevitable that these techniques will have less range. While the state of affairs for the forward visibility technique has been mentioned, there is also an inherent range penalty in using the multi-ratio forward scatter method. In this case, the larger of the two or more, observation angles determines the upper limit for the measurable particle size. As this is reduced to increase the range upward, the smaller angle must be proportionately reduced, possibly resulting in practical difficulties in stopping the beam and achieving a satisfactory collection aperture size. Thus, it appears that the need for two instruments, or a least two different optical systems, will be more pressing for a ratio type instrument than for one based upon reception at a single scatter angle. Before leaving this subject, it is interesting to note that the ambiguity due to the multi-valued nature of the small angle near forward scattered (SANFS) signal's diameter dependence begins in the size range at which the visibility ratio simultaneously falls and remains below a value determined by the receiver field of view. Thus a FV signal above the threshold value would restrict measurements within a size range where the SANFS signal is single valued.

The large dynamic range (1000:1) of the scattered intensities for even a relatively small size range ( $0.5-15$ microns) requires that the detection and signal processor electronics must also have a very large dynamic range. This is also true of ratio schemes which utilize the ratio of detected intensities.

Another practical limitation imposed by single particle counting methods is the ability to measure narrow pulses, in particular random pulses occurring at a high duty cycle ratio. In the case of pulsed signals due to particle scattered light, the large dynamic range of the signals further exacerbates the situation. A variety of signal processing circuits is required including electronic multipliers and dividers or their equivalent. While linear amplifiers are readily available with adequate bandwidth, some of the other needed components are not. Some components have been developed for application in military electronics and nuclear instrumentation which are useful. However, they are expensive and not easily used. Furthermore, the random nature of the signals compounds the difficulty in applying AC-coupling and pulse stretching techniques for wide bandwidth, wide dynamic range signals. Such techniques, when applicable, are quite useful for combatting drift problems and extending the 
dynamic performance, otherwise these problems must be dealt with by other, more complex means. The reality of this situation is quickly grasped by considering the effect of a baseline shift produced by AC-coupling circuits upon determining the pulse height of a small pulse immediately following a larger one.

Finally, multiple particles in the sampling volume produce a difficulty not altogether resolvable. If this condition exists due to an overload, then the overload can most likely be detected so that the operator of a system can be warned of the problem. If the condition is simply an inevitable but sporadic occurrence, then a small particle will be hidden by a larger one and not detected. Thus, measurements are biased to shift a distribution in favor of larger particles. The sensitivity of the system and the background DC signal due to ensemble scattering from the more numerous and unresolvable smaller particles also set a lower limit for the detectable particle size; hence, any distribution function based upon measurements will be truncated at the lower end of the size range. 


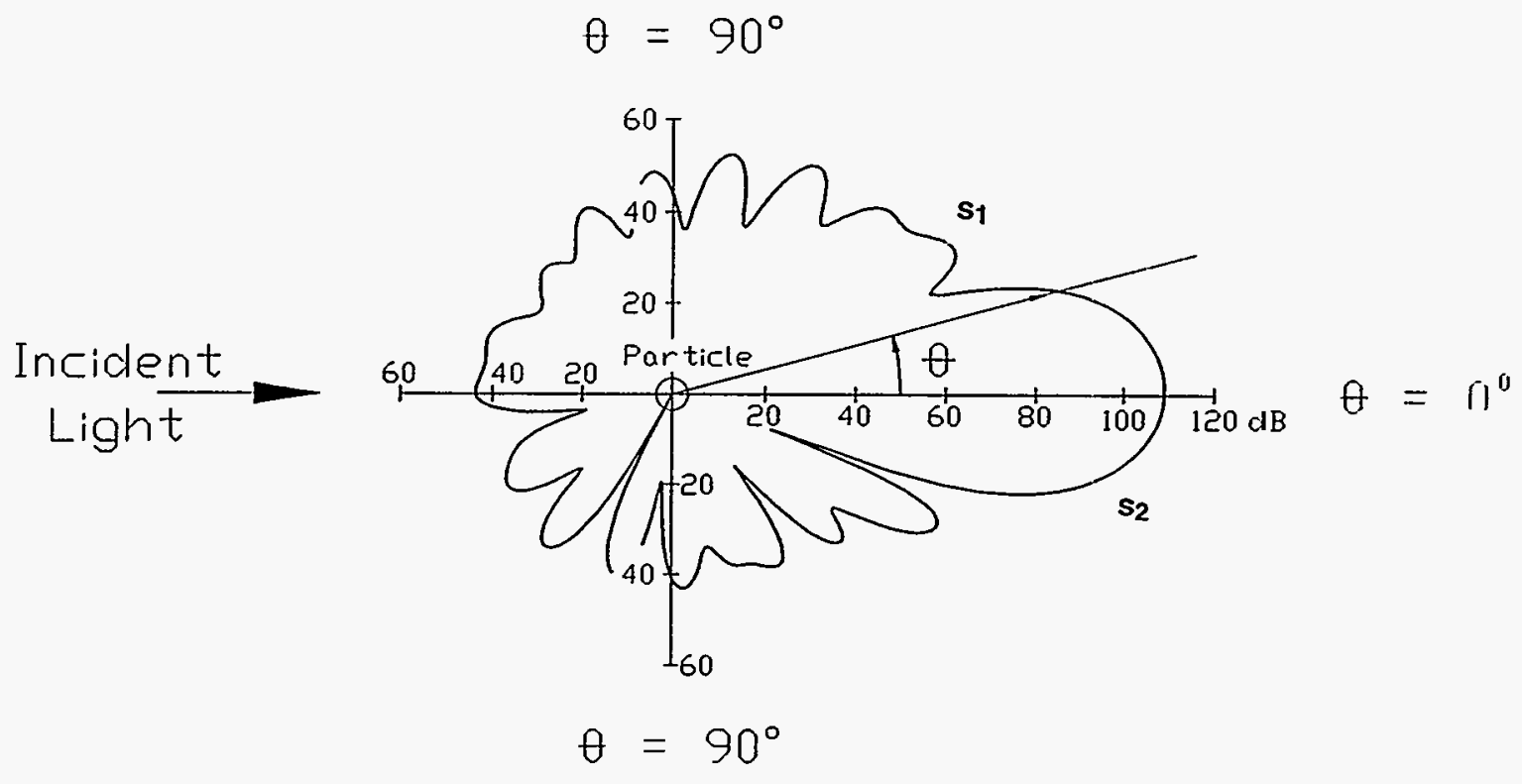

Figure 1. Polar diagram of Mie scattering response for a particle. 


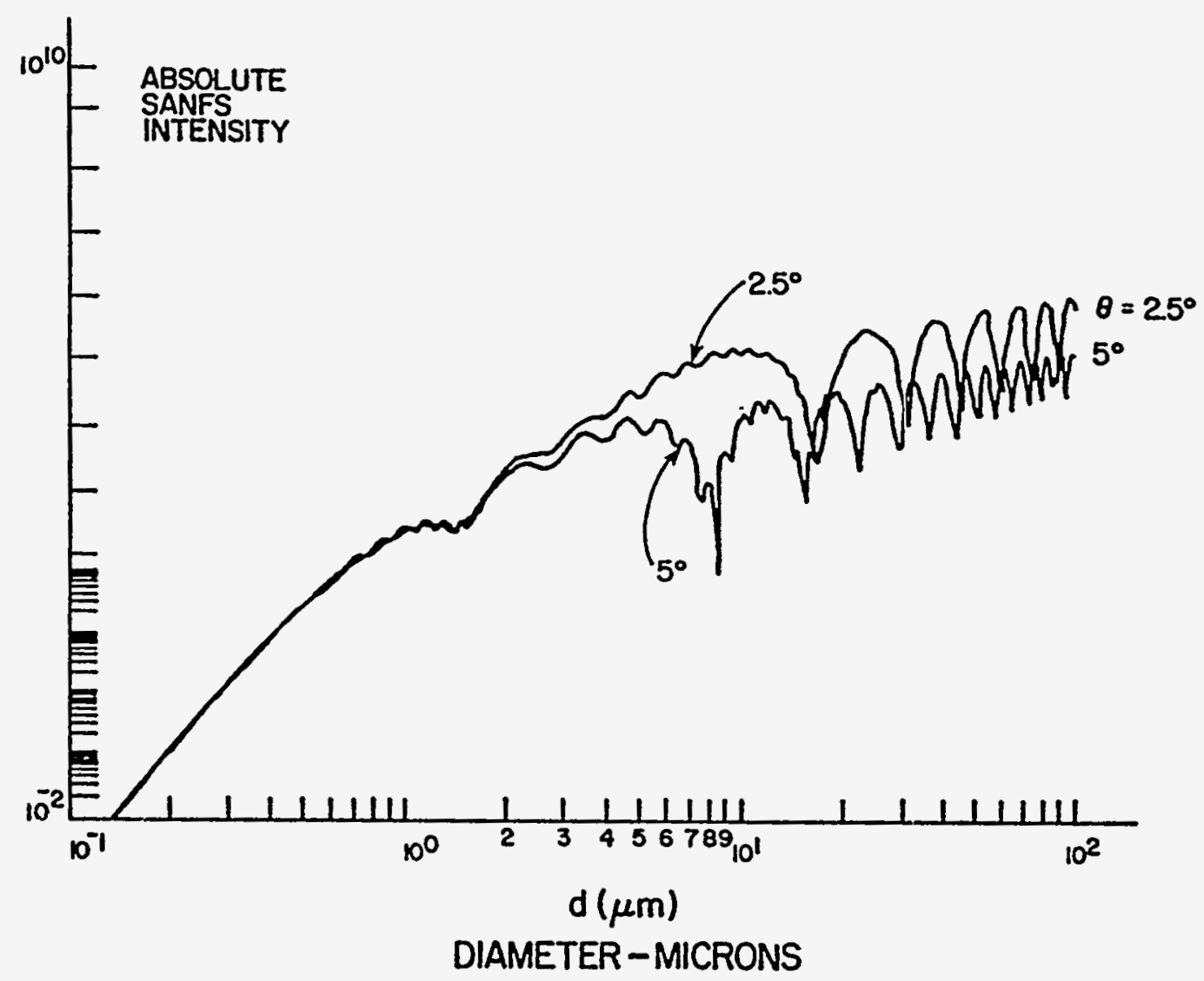

Figure 2. SANFS signal relationship. 


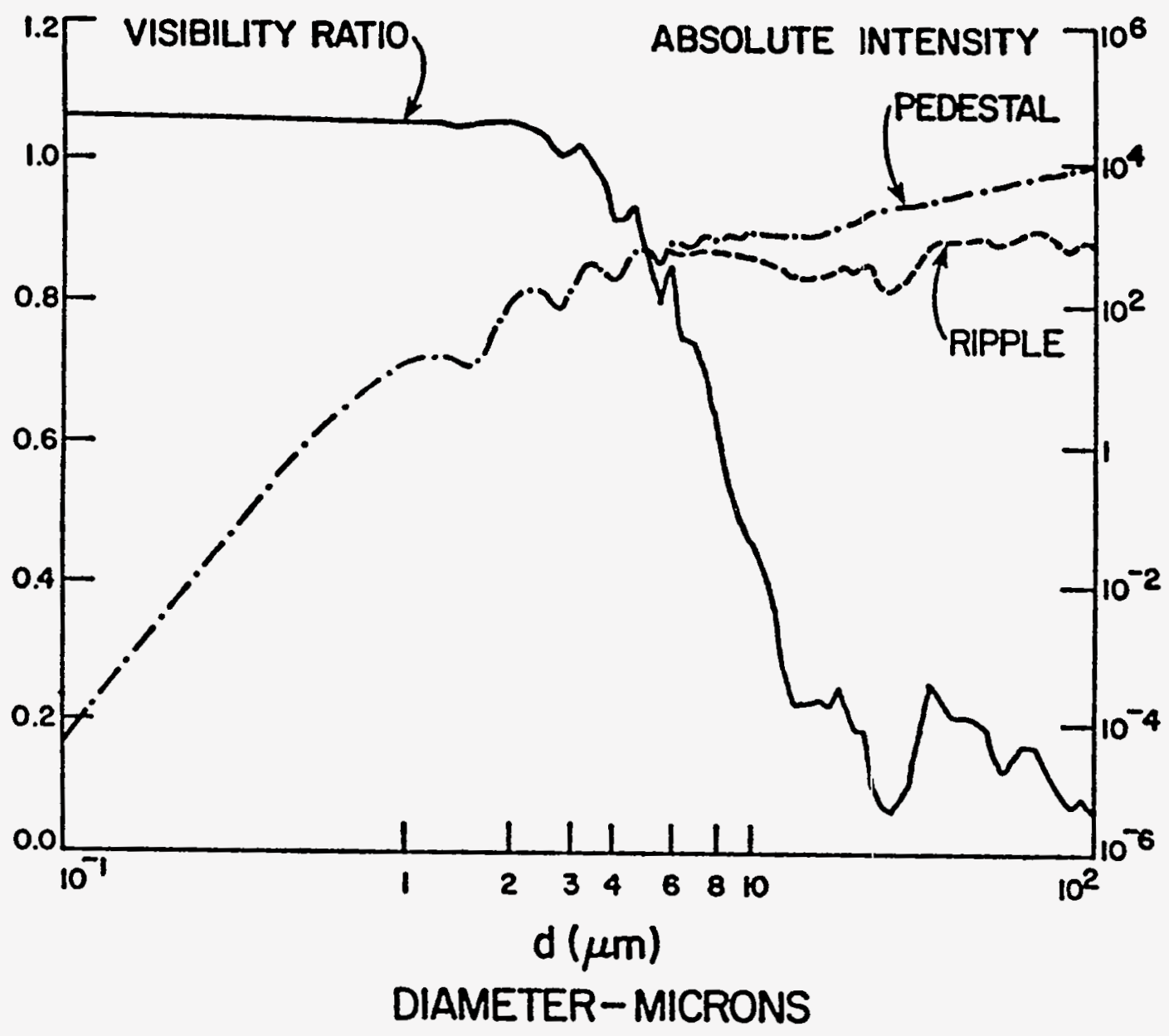

Figure 3 . Visibility signal relationship. 


\section{SYSTEM DESCRIPTION}

The hybrid system chosen for implementation in the instrument incorporates three techniques in order to increase the measurement range: (1) ripple validated small angle near-forward scattering (RVS), (2) small angle near-forward scattering (SANFS) deconvolution, and (3) ripple deconvolution (RDM). This section describes four different aspects of the design: (a) the mechanical support frame, (b) the electro-optical system, (c) the signal processor, and (d) the computer system for data collection, analysis, display and control functions. A schematic of the instrument is shown in Figure 4.

\section{Mechanical Support Frame}

The electro-optical system is mounted on a rigid bench so that alignments can be made before the instrument is deployed for measurements. This bench in turn is mounted on a movable frame which has casters and jacks to move the system into position and then stabilize it. The bench can be moved linearly along two axes and rotated about two. The combined motion allows the instrument to be placed at a port, after which the sample volume can be scanned for approximately six inches across the flow channel. Problems with the system are that the adjustable height does not allow for use along the entire length of the test channel. A second problem is that cooling pipes on the hot sections stick down reducing the clearance between the channel and the support frame to zero.

\section{Electro-optical System}

The electro-optical system consists of a $500 \mathrm{~mW}$ multimode laser, a color separator, transmission optics, reception optics, two photomultipliers, and one photodiode sensor system. The transmission and reception optics, illustrated schematically in Figure 5, will be briefly discussed.

The transmission optics provide a single green beam for the RVS and SANFS measurement and two crossed blue beams for the RVS and RDM measurement. A customized beam expander provides for expanding the blue beams without expanding the green. Thus, a smaller blue sample volume is created concentrically within a larger green one. This is an important feature in the implementation. 
The receiving optics separate the green and blue optical signals through use of a dichroic mirror, and two narrow band interference filters at the photomultiplier entrance. Two opaque masks further define segments of an angular pattern for the RVS and SANFS sizing signals and two symmetrical rectangular openings for the blue RDM sizing and RVS validation signal. A dichroic mirror separates the two-color images, after which the respective laser line bandpass filters further attenuate the off-color signal while transmitting the selected color.

The receiving optics also redirects the central green beam with a mirror to a photodiode detector. The output of this detector is used to indicate out of tolerance beam conditions and also to provide a normalizing base signal for the sizing signals.

\section{Transmission Optics}

The system of transmission optics consists of components developed by TSI, Inc. for use in their laser Doppler velocimeter instruments. The purpose of this system is to provide the three beams, two blue and one green, with control over the beam diameters, beam alignments, and beam intensities. The beam expander was customized by drilling a centerline hole that allows the central beam to pass through without being expanded. All other components are standard items available from TSI, Inc. Figure 6 is an optical schematic which identifies all of the components, including a light chopper not supplied by TSI, Inc. Further information on these components is available in the Laser Velocimeter Systems Catalog 28 and the System 9100-7: Laser Doppler Velocimeter Instruction Manual29 both from TSI, Inc. The LDV Manual should be consulted for details concerning alignment procedures. Operation of the transmission optics will be discussed in the following by tracing the laser beam components from the output of the laser to the output of the focussing lens.

The laser beam which emerges from the laser is passed through a rotating disk with radial slots and spokes which block the beam. This chopper provides alternating periods during which the beam is blocked and the scattered light signal's baseline is restored to compensate for drift in the photomultipliers and input stage electronics of the signal processor. This is discussed in the section which describes the signal processor. 
The beam goes to a collimator fabricated in house which expands the beam by about 1.5 times. It is adjusted to position the focused beam waist at the point where the beam centerlines intersect.

The beam then enters into the color separator which is specified as an assembly which includes the following: (a) polarization rotator, (b) attenuator, (c) color dispersion prism set, (d) three mirrors, and (e) a shroud which serves as a dust cover and for protection of the components. The polarization rotator and attenuator are used to control the intensity of the beam entering the dispersion prism. The attenuator has been modified to reflect the unused beam to a silicon photodetector assembly to provide a beam chopper synchronization signal. The dispersion prism set separates the multiple laser line colors using the variation of the prism material's refractive index with wavelength to produce different angles of refraction. The separated beam components then strike a flat mirror which reflects them toward two 90 degree mirrors. After traversing the distance to these mirrors the beams are well separated so that one mirror receives only the $488 \mathrm{~nm}$ blue beam and the other receives only the $514.5 \mathrm{~nm}$ green beam, all other beams are blocked. All of the optical components are aligned to make these two beams enter into the forward transmission system approximately parallel with the optical axis and with proper spacing which is facilitated by a pair of alignment templates with holes used to locate the beams.

The green beam enters the optical barrel assembly on-axis and passes through a polarization rotator which is used to obtain proper polarization of the beam. Then the green beam is then shifted off-axis by a prism mirror to make room for the blue beam.

The blue beam enters off-axis and is then shifted on-axis by a prism mirror at a point in the transmission path after the point where the green beam is shifted off-axis. The relative beam placements are shown in Figure 6. After being shifted on-axis, the blue beam also passes through a polarization rotator which can be used to tune the balance power between the two blue beams which emerge from the beam splitter. An optional optical attenuator can be put in the blue beam before the beamsplitter assembly if needed. The blue beam then enters a beam splitter which produces two beams which are approximately of equal intensity, each with $25 \mathrm{~mm}$ offset from the barrel axis. Each beam then passes through a beam steering module which consists of a pair of movable optical wedges that can be adjusted to make the beams travel precisely parallel with the optical axis. 
The green beam is then shifted back on-axis where it then passes on through the hole in the expander to the transmission lens. The blue beams travel from the beam steering modules to a beam spacer. The beam spacing was chosen to be $22 \mathrm{~mm}$ but can be later changed to either $9 \mathrm{~mm}$ or $35 \mathrm{~mm}$ by changing this module (TSI Model No. 9113-22). Thereafter, the beams enter a $3.75 x$ expander. This consists of diverging and collimating lens which cause the diameter and separation of the blue beams to be increased by a factor of 3.75 .

Finally, all of the beams reach the transmitting lens. This is a $480 \mathrm{~mm}$ focal length (FL) lens with a clear aperture $152 \mathrm{~mm}$ in diameter. This produces an intersection angle of approximately 10 degrees with 38 interference fringes (between the $1 / \mathrm{e}^{2}$ points of beam intensity) at the focal region.

\section{Receiving Optics}

The receiving optics system was also developed using many of the components supplied by TSI, Inc. Consequently, the TSI LDV Systems Catalog28 and the System 9100-7: LDV Instruction Manual29 should be consulted for details beyond those given in this section. Significant modifications of the standard TSI, Inc. components have been made and are discussed in the following and elsewhere as will be noted. Figure 7 is a optical schematic which will be used as a basis for describing the system in the following. The optical path will be traced from left to right, beginning with entry into the receiving lens.

The 9119 receiving lens has $600 \mathrm{~mm}$ FL and a $60 \mathrm{~mm}$ clear diameter. This lens is placed with its focal point at the focal point of the transmitting lens so that it collimates the light scattered by the particles. Thus, all collected rays of scattered radiation exit the lens essentially parallel with the optical axis. The central green beam also is transmitted through the lens.

The 9140-K modified receiving assembly consists of the barrel of a 9140 assembly with a mirror mount modified for particle size measurement applications. The assembly serves to route the green on-axis beam to a photodetector. The standard mirror mount was replaced with a clear window with the mirror mount glued to its center to allow a collection of light in the near forward direction. The function of the mirror is obviously to redirect the green beam to the TSI Model No. 9150-A detector. This is 
produced by Newport Research Corp. (NRC Model No. 882) and is supported with a laser power meter (NRC Model No. 820). An amplifier has been constructed to replace the meter assembly and allow the computer to read the laser power. The TSI 9150 mount has been customized to receive the detector.

The image of the collimated scattered light from receiving lens (60 $\mathrm{mm}$ diameter) is too large to project onto the dichroic mirror and; therefore, an adjustable telescope was fabricated to reduce the image. Ideally, the rays entering and exiting the device are parallel.

The dichroic mirror is specified to have a transmission efficiency (green signals) of 85 percent and a reflection efficiency (blue signals) of 95 percent.

The reflected and transmitted light are passed to two mask holders. The reflected blue light is passed to a mask with two rectangular openings spaced such that they gather light at the angle of about 2.5 degrees inside the blue beams. The geometry was chosen after computer analysis of the visibility response of various geometries. The transmitted green light is passed to a mask with an annular ring scaled to collect light at an angle of about 1.5 degrees. Both masks are constructed by placing the red part of Rubylith onto $63 \mathrm{~mm}$ diameter windows, then carefully cutting out the open areas with a knife. In the case of the circular cuts, the knife is mounted in a compass.

The separated images are collected by the respective photomultiplier tube (PMT) receiver assemblies (TSI Model No. 9140) which focus the collimated light onto the pinholes of the photomultiplier assemblies. The PMT receiver has both a 90 degree mirror and a $22 \mathrm{~mm}$ FL lens and an overall transmission efficiency of 98 percent. At the exit of the PMT receiver assemblies there are laser line interference filters with a peak transmittance of 80 percent and full width at half maximum (FWHM) of $6.4 \pm 1.3 \mathrm{~nm}$ (green) and $6.1 \pm 1.2 \mathrm{~nm}$ (blue).

Each photomultiplier tube assembly consists of a $0.2 \mathrm{~mm}$ diameter pinhole aperture for limiting the field of view, and an RCA 4526 PMT. This PMT has a multialkali cathode which produces a relatively flat response and high quantum efficiency at the wavelengths of interest (488 $514.5 \mathrm{~nm}$ ). It is a side entrance tube with dormer-type windows and has 
characteristics as listed in Table III. The response of the tube is also dependent on where the light hits the cathode.

Table III. Photomultiplier Tube Specifications.

\begin{tabular}{|c|c|}
\hline Number of Dynodes & 10 \\
\hline Max. High Voltage, HV & $2 \mathrm{kV}$ \\
\hline Max. Average Anode Current & $100 \mu \mathrm{A}$ \\
\hline Current Multiplication, $\mathrm{M}$ & 50,000 \\
\hline Cathode Sensitivity, $\mathrm{J}_{\mathrm{K}}$ & $\begin{array}{l}90 \mathrm{~mA} / \mathrm{W}(50-90 \text { range }) \\
\text { and } 300 \mu \mathrm{A} / \text { lumen }\end{array}$ \\
\hline $\begin{array}{l}\text { Anode Sensitivity, } S_{A} \\
(H V=-1250 \mathrm{~V})\end{array}$ & $4.4 \mathrm{~A} / \mathrm{mW}$ and $15 \mathrm{~A} /$ lumen \\
\hline $\begin{array}{c}\text { Overall Response, GPMT } \\
\text { (w/transconductance, } \\
\mathrm{G}_{\mathrm{T}}=22 \mathrm{~V} / \mathrm{mA} \text { ) }\end{array}$ & $97 \mathrm{~V} / \mu \mathrm{W}$ and $330 \mathrm{KV} /$ lumen \\
\hline Anode Rise Time, TR & $2 \mathrm{nsec}$ \\
\hline $\begin{array}{c}\text { Bandwidth, BW } \\
\text { (w/Harris 5195 preamp) }\end{array}$ & $5 \mathrm{MHz}$ \\
\hline $\begin{array}{c}\text { Anode Dark Current, } \mathrm{I}_{\mathrm{d}} \\
\left(@ 22^{\circ} \mathrm{C} \text { and } \mathrm{S}_{\mathrm{A}}=20 \mathrm{~A} / \text { lumen) }\right.\end{array}$ & $2 \mathrm{nA}$ \\
\hline
\end{tabular}

Each PMT assembly is supported with a TSI Model No. 9165 power supply/anode current overload protector and electronic preamplifier. The two power supplies are mounted in a 19 inch rack chassis along with the power supplies for the signal processor. The voltage controls for the PMT supplies were replaced with the ten turn potentiometers which are mounted on the front panel. Rotary position counters are mounted on these potentiometers to allow precise setting of the high voltage applied between the photocathode and the anode. This is very important in maintaining the sensitivity of the PMT because of its power law dependence as shown in Figure 8.

An electronic amplifier is mounted at the base of each PMT assembly. This is a transconductance amplifier which is used to convert the anode current to the voltage signal transmitted to the signal processor through a 
$50 \mathrm{~W}$ coaxial cable. The PMT assemblies as delivered by TSI had an AC-coupled amplifier with a bandwidth of $400 \mathrm{MHz}$. These amplifiers (Avantek) were replaced with Harris Corp. units which are DC-coupled. These amplifiers, HA5195, have a bandwidth of $5 \mathrm{Mhz}$ (@ $\mathrm{G}_{\mathrm{T}}=22 \mathrm{~V} / \mathrm{mA}$ ) which is adequate for the flow velocities on the DIAL combustion test stand and at 's CFFF ESP/BGH exit ducts.

The data shown in Table IV characterizes the receiving optics in terms of overall effective collection angle or aperture area. The calculation for each color is based upon the actual aperture and the optical efficiency of the various optical components. Both approaches are of some use in estimating the SANFS signal; however, calculation of the ripple and pedestal signals requires additional considerations. A direct comparison of the two parameters is not meaningful in an absolute sense.

Table IV. Scattered Light Receiver Parameters

\begin{tabular}{||c|c|c||}
\hline PARAMETER & SANFS & RIPPLE \& PEDESTAL \\
\hline $\begin{array}{c}\text { Collection Angle, } \\
\text { Steradians }\end{array}$ & 0.00031 & 0.00158 \\
\hline $\begin{array}{c}\text { Collection Aperture, } \\
\text { cm }^{2}\end{array}$ & 1.10800 & 5.67000 \\
\hline $\begin{array}{c}\text { Separation Filter } \\
\text { Efficiency }\end{array}$ & 0.98000 & 0.60000 \\
\hline $\begin{array}{c}\text { Dichroic Mirror } \\
\text { Efficiency }\end{array}$ & 0.85000 & 0.95000 \\
\hline $\begin{array}{c}\text { Receiving Mirror } \\
\text { Efficiency }\end{array}$ & 0.98000 & 0.80000 \\
\hline $\begin{array}{c}\text { Laser Line Interference } \\
\text { Filter Efficiency }\end{array}$ & 0.80000 & 0.07060 \\
\hline $\begin{array}{c}\text { Effective Collection } \\
\text { Angle, Steradians }\end{array}$ & 0.02020 & 2.53000 \\
\hline $\begin{array}{c}\text { Effective Collection } \\
\text { Aperture, cm }\end{array}$ & 0.72200 & \\
\hline \hline
\end{tabular}


The data in Table IV can be used to obtain a rough estimate of the SANFS pulse amplitude, es, for a given particle size by applying it in the following formula

$$
\mathrm{e}_{\mathrm{s}}=\mathrm{SR} \cdot\left(\frac{\lambda}{2 \pi \mathrm{f}_{\mathrm{R}}}\right) \cdot\left(\frac{\mathrm{I}^{\prime}}{\mathrm{I}}\right) \cdot \mathrm{A}^{\prime} \cdot \mathrm{G}_{\mathrm{PMT}} \cdot \mathrm{I}
$$

where the factors are explained as follows: SR is the normalized SANFS response obtained from Mie scatter calculations. Applying this to an annular aperture and assuming the laser beam has equal electric field components in each direction perpendicular to the direction of propagation (beam is unpolarized), then SR is given by the Mie parameters

$$
S R=\frac{S_{1}^{2}+S_{2}^{2}}{2}
$$

which have been calculated by Luthe. 30 (Actually, the polarization of the field should be accounted for since only a partial annulus is used.) Luthe's calculations give $S R=0.25 \times 10^{6}$ for a 5 micron particle. The factor $\lambda /\left(2 \pi f_{R}\right)$ arises in the calculation as $1 / \mathrm{kR}$, the product of the wavevector, $k$, and distance from the scattering particle to the observation point, which in this case is approximately the focal length of the receiving lens, $R=f_{R}$. The factor $I^{\prime} / I$ is associated with the increase in beam intensity as the beam is focused.31 For the case where the beam entering the focusing lens is collimated, the spot size reduction is given by

$$
\frac{\omega^{\prime}}{\omega}=\frac{\mathrm{f}_{\mathrm{T}} \lambda}{\pi \omega^{2} \mathrm{n}}
$$

where $\omega^{\prime}$ is the laser beam waist radius at the focal point, $w$ is the waist entering the transmitting lens, $\mathrm{f}_{\mathrm{T}}$ is the focal length of the transmitting lens, $\lambda$, is the wavelength, and $n$, is the refractive index of the medium ( $n$ $=1$ in this case). The increase in intensity is given by

$$
\frac{I^{\prime}}{I}=\left(\frac{\pi \omega^{2} n}{f_{T} \lambda}\right)^{2} \text {. }
$$

15601-TR-13-PSD-6-94 
$A R^{\prime}$ is the effective collecting aperture area. It may be noted also that $A_{R}{ }^{\prime} / f_{R}{ }^{2}$; is the aperture solid angle measured in steradians. Therefore, the formula can be expressed either in angular dimensions or area dimensions for the aperture. GPMT is the photomultiplier sensitivity. The value given previously should be considered an upper limit based on data provided by both RCA and TSI, Inc. The actual unit has a cathode bias control which adjusts the sensitivity. The peak intensity, I, of a Gaussian beam is given in terms of the total power, $P$, and beam waist radius, $\omega$, as

$$
I=\frac{2 P}{\pi \omega^{2}} \text {. }
$$

It is of interest to apply the formula to an experimental situation in which light scattered from a 5 micron pinhole was measured. In this case, the laser (Spectra-Physics Model 162A) power in the green line was approximately $4 \mathrm{~mW}$; the beam waist at the focal point was measured to be 2 mils $(0.079 \mathrm{~mm})$; the receiving area, $A_{R}{ }^{\prime}$ was $3 \mathrm{~cm}^{2}$; and the cathode control was set to 0.35 (PMT high voltage $=-650 \mathrm{~V}$ ). The measured pulse height in this case was approximately $60 \mathrm{mV}$. Calculations for this case, assuming pinhole scattering to be approximately the same as for a particle (diffraction from the edges of the circle), give the following

$$
\begin{gathered}
\mathrm{SR}=0.25 \cdot 10^{6}, \frac{\lambda^{2}}{4 \pi \mathrm{f}_{\mathrm{R}}^{2}}=1.76 \cdot 10^{-14} \\
\mathrm{I}^{\prime}=\frac{2 \cdot 4 \cdot 10^{-3}}{\pi \cdot 0.0079}=40.8 \frac{\mathrm{W}}{\mathrm{cm}^{2}} \\
\mathrm{~A}_{\mathrm{R}}^{\prime}=3 \mathrm{~cm}^{2} \cdot 0.664=2 \mathrm{~cm}^{2} \\
\mathrm{G}_{\mathrm{PMT}}=0.3 \frac{\mathrm{V}}{\mu \mathrm{W}},(\text { PMT High Voltage }=650 \mathrm{~V}) \\
\mathrm{e}_{\mathrm{s}}=0.25 \cdot 10^{6} \cdot 1.76 \cdot 10^{-14} \cdot 40.8 \cdot 0.3 \cdot 10^{6}=54 \mathrm{mV} .
\end{gathered}
$$

There is a large disagreement in these results, and it is instructive to consider the possible errors: (1) diffraction from a pinhole will produce less scattered light than a particle; (2) losses due to reflection at the surface 
of all the optical elements have been neglected; and (3) the optical filters and dichroic mirror were assumed to have a transmittance of one. The quantities $I^{\prime}, A_{R}$ and $G_{P M T}$ are fairly accurate.

\section{Signal Processor}

The fundamental basis for processing the signals is multichannel pulse height analysis. The signal processor consists of two 4096-channel analyzers, one recording peak SANFS signals and the other peak ripple signals. Both analyzers are implemented on a single S-100 bus plug-in card. A commercially available S-100 parallel port interface card is used as an auxiliary to provide address decoding and data transfer to memory capability. The speed of the analyzer is limited by that of the analog to digital converter (ADC), but it is anticipated that it will be fast enough to accommodate the data rates expected.

The analyzers are fed by two-stage peak detectors with good acquisition and hold characteristics and are clocked by two separate clock signals generated in the sampling clock logic module. The basis for one clock is the SANFS peak detector, which is the most sensitive element in the signal paths. This clock is further qualified by logic based upon amplitude comparison and sequential timing. The amplitude comparison determines whether the signal is in range for an unambiguous measurement and, if so, whether it is in the range to be registered as a valid SANFS signal. The sequential logic tests for multiple triggering of a comparator in the SANFS peak detector and for dropout of the ripple counter in an attempt to eliminate multiple particle measurements.

The most important elements of the signal processor are the logarithmic amplifiers which are used in receiving the signal from the photomultipliers and in performing the equivalent ratioing operation (subtraction of logarithms). The typical high accuracy instrumentation logarithmic amplifier is too slow. Some such circuits have been modified to improve the speed for the optical applications; however, these amplifiers are also lacking in performance. The logarithmic circuits devised for radar applications have the necessary speed; however, they are not true logarithmic amplifiers, but are AC-coupled, and must be used with care. These circuits require a number of adjustments which are critical in order to achieve the accuracy of which they are capable, typically, to within 0.5 $\mathrm{dB}$. They are also expensive and not necessarily optimized for application to particle sizing. Therefore, it was decided to develop custom amplifiers 
of this type. This approach allowed some flexibility in optimizing tradeoffs in drift and speed performance and also in configuring both the input and output circuits as well as the overall circuit package. Three different types of high speed log amp were developed, two of which have approximately $60 \mathrm{~dB}$ range and differ from one another mainly in that one, which processes ripple bursts, is AC-coupled and the other DC-coupled, and a third type which has a range of approximately $74 \mathrm{~dB}$. When properly aligned, the amplifiers achieve log linearity to within $0.5 \mathrm{~dB}$ over their respective ranges and for frequencies in excess of $1 \mathrm{MHz}$. They will process pulses of microsecond width with little dynamic distortion.

In order to take advantage of the DC-coupled logarithmic amplifiers, the PMT signals are first passed through baseline restoration circuits which cancel out drift and bias offset from the PMT amplifier. The restoration circuits are synchronized to a light chopper so that during dark periods sensitive integrators are connected to track and washout the input offset. During the illuminating periods, these circuits are placed into a hold mode. This scheme for maintaining the baseline is compatible with the requirements set by other signal processing functions.

Figure 9 shows a functional block diagram for the signal processor. Some features, such as the ripple-pedestal separator, are quite similar to those of instruments reported by others. The instrument does take advantage of having the ripple signal available for determining the particle velocity; however, there are other significant novelties in the design. First, it should be noted that the separated pedestal signal is processed by two different logarithmic (log) amplifiers, one which operates on the lower level signals and a second which a wider range. The output of the logarithmic ripple detector is subtracted from the output of the lower range pedestal log-amplifier to obtain the log visibility signal. The output of the wide range amplifier is peak detected and compared with the peak detected signal from the SANFS log amp. Peak signals will be registered only when the ratio of pedestal peak to SANFS peak exceeds a certain threshold which guarantees that the particle trajectory from the center of the SANFS probe volume is within a prescribed limit. The test for validity of the signal is effective because the probe volume for the pedestal signal, which is formed in part by the physics of the crossed blue beams, is well within the probe volume for SANFS (green) signal. The test could be applied more stringently by peak detecting the logarithmic differences; however, the present scheme is effective and simpler to implement. 
In addition to the features mentioned thus far, the computer can select either the SANFS or the ripple deconvolution peak signals at the input of the ADC, which performs the quantization task of the overall pulse height analyzer function achieved by the signal processor. 


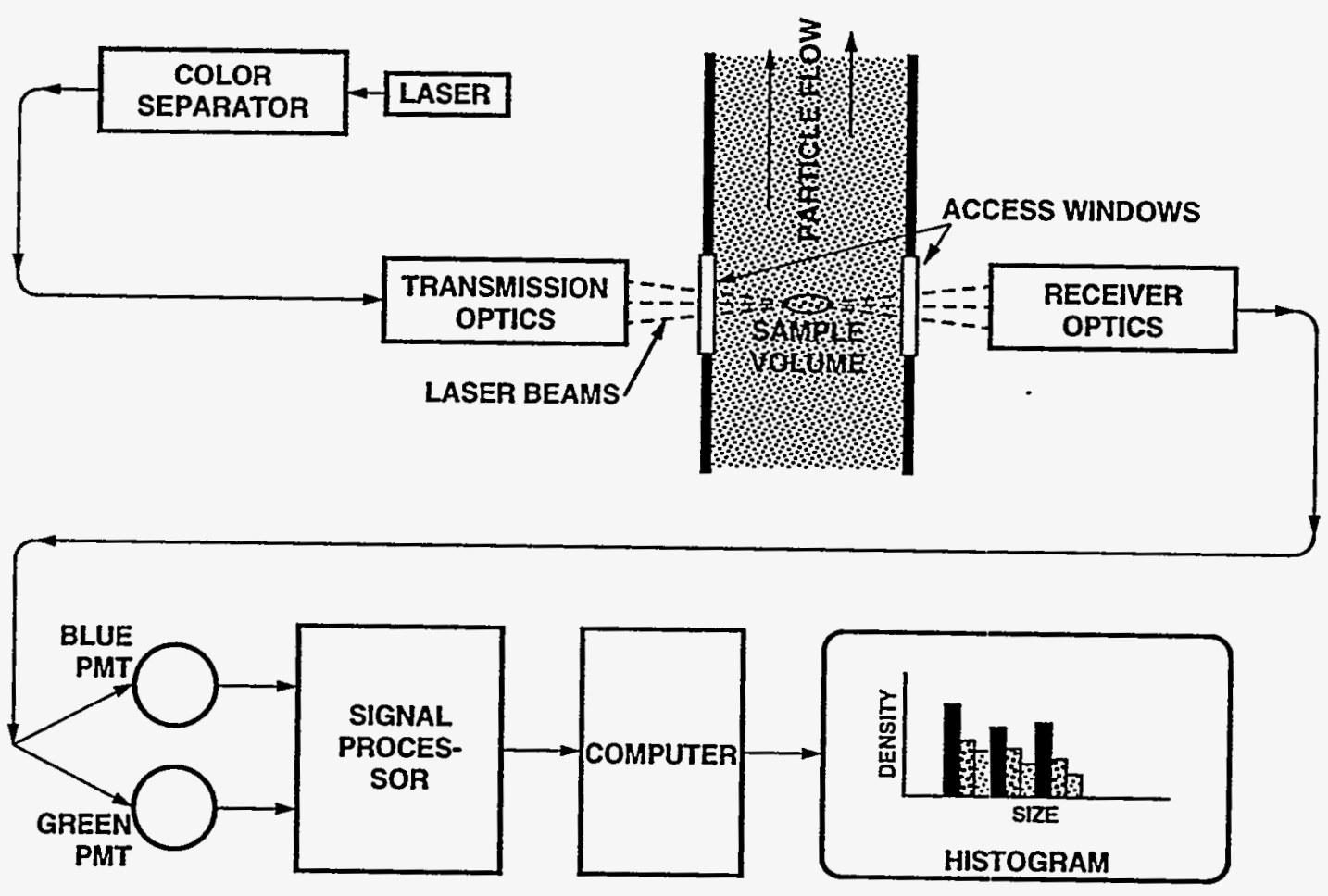

Figure 4. Block diagram of PSD instrument. 


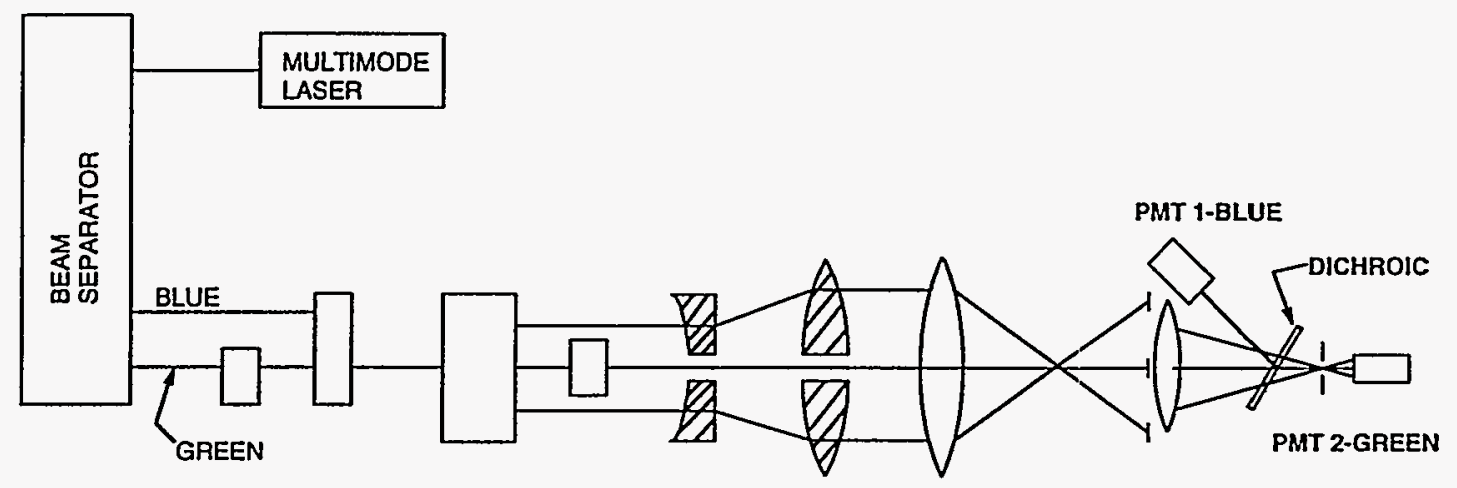

Figure 5. Optical system. 


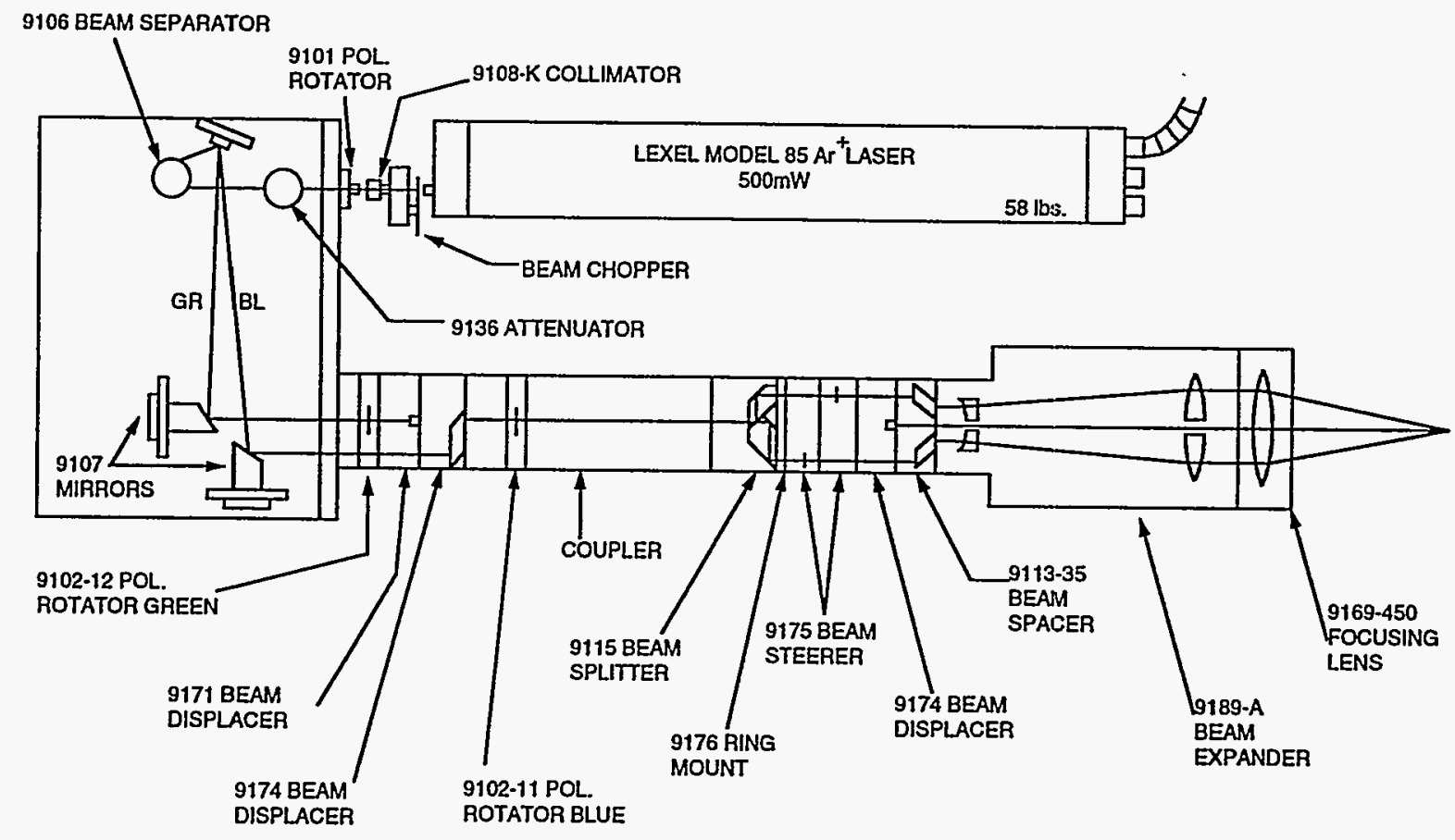

Figure 6. Transmission optics. 


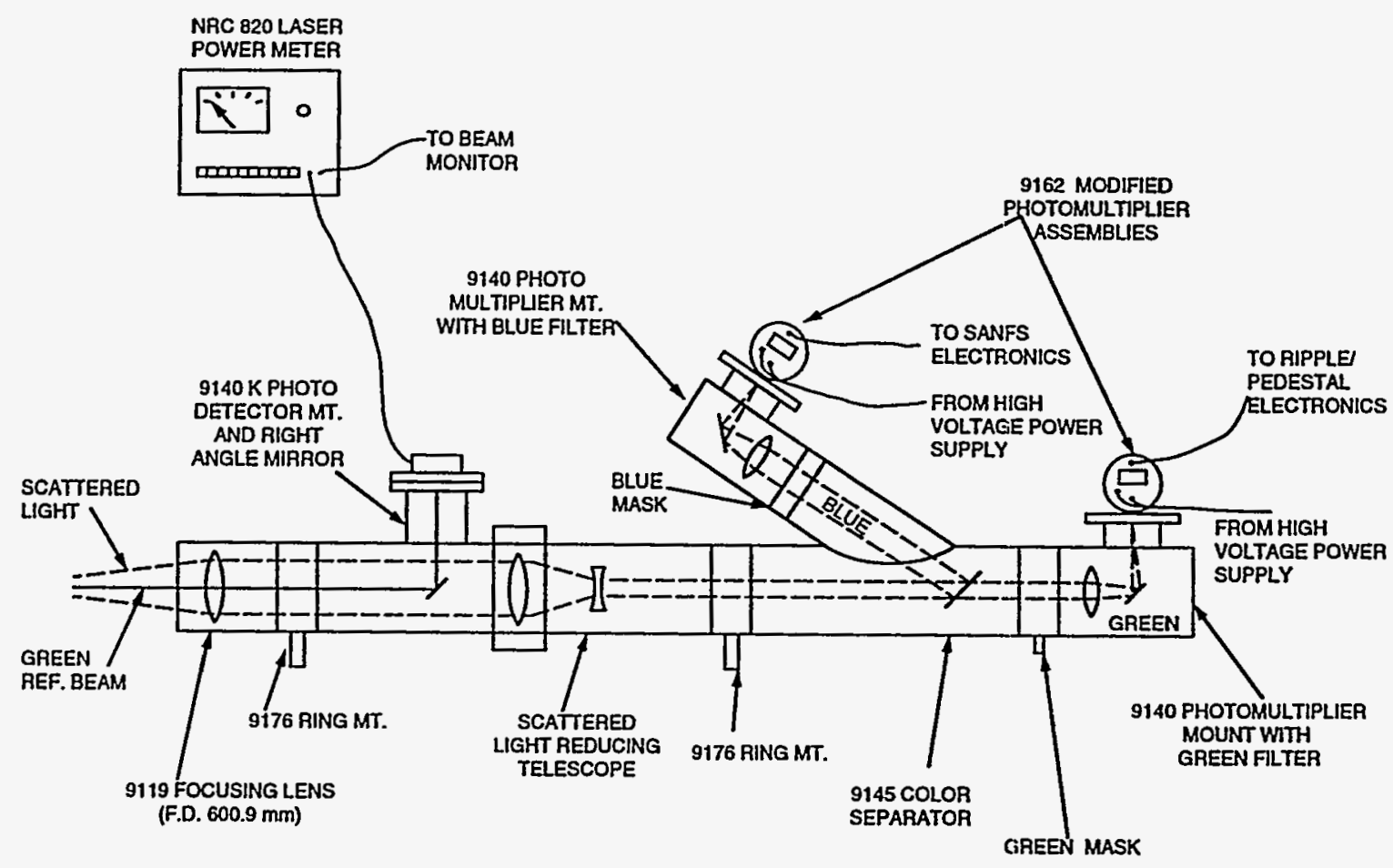

Figure 7. Receiving optics. 


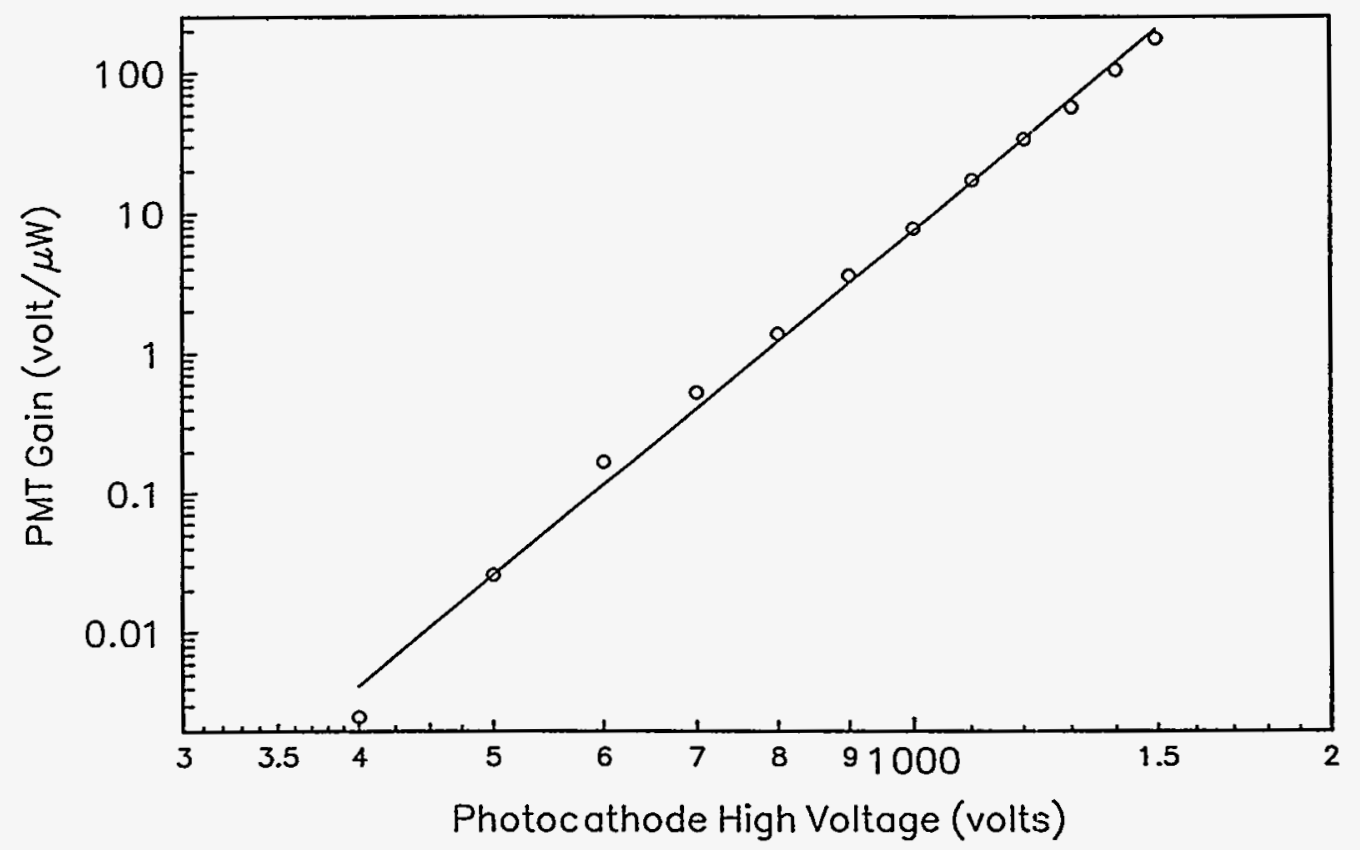

Figure 8. Photomultiplier tube gain vs. photocathode high voltage. 


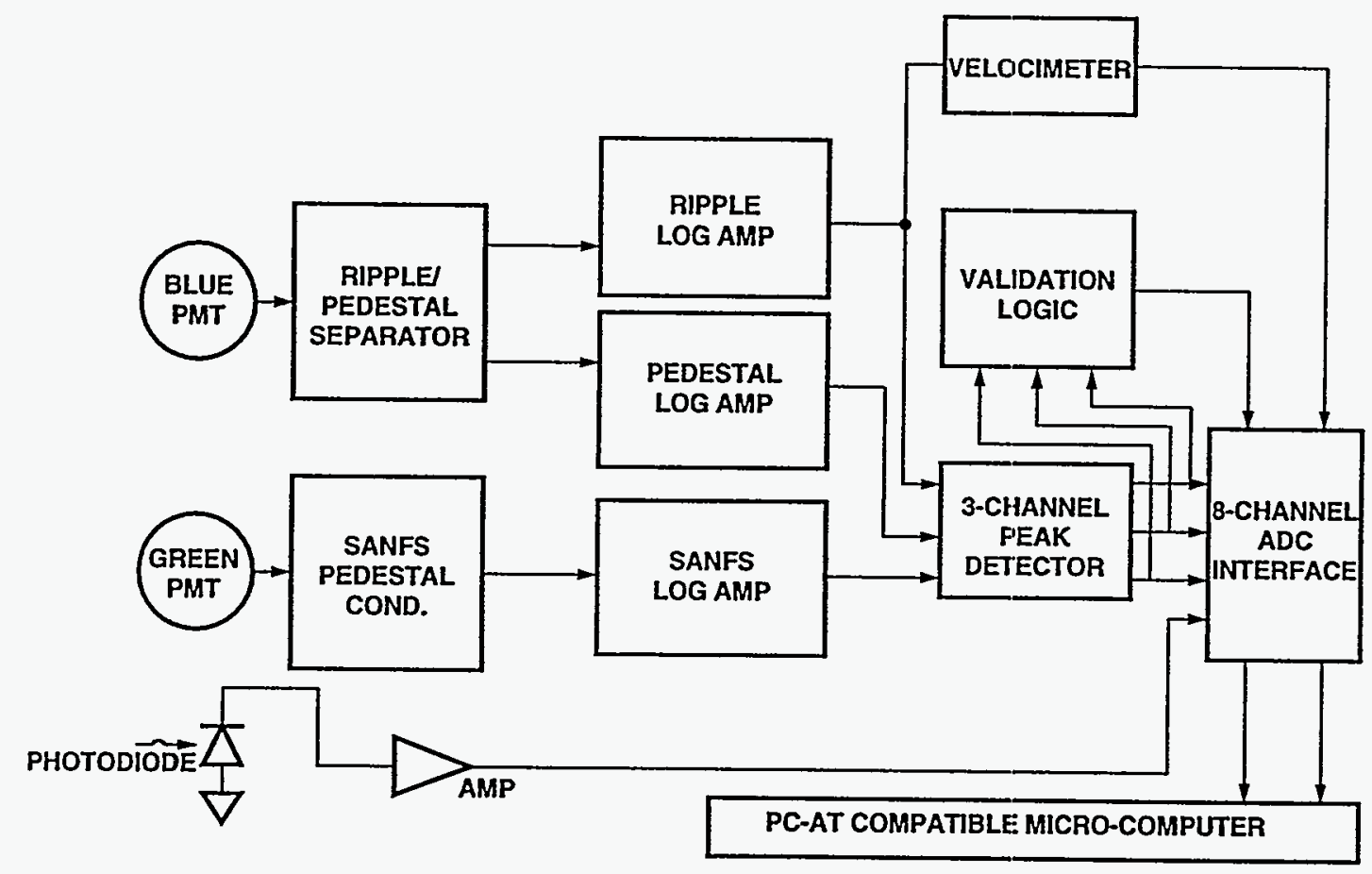

Figure 9. Block diagram for PSD signal processor. 


\section{INSTRUMENT MODIFICATIONS FOR FIELD MEASUREMENTS}

The prototype instrument design was extensively modified to perform measurements at DOE's CFFF. All four major subsystems were modified to improve the instrument's utility under field measurement conditions. A new mechanical support frame of simpler construction was designed and constructed. The electro-optical system was modified to accommodate a larger flow channel and facilitate alignment under field conditions. A more flexible signal processor was designed and fabricated using printed circuit construction techniques. The original computer was replaced by an IBM AT compatible microcomputer. During the summer of 1987 a preliminary configuration was assembled to make measurements at the CFFF electrostatic precipitator exit duct during August. Although this initial field configuration was difficult to setup, align, and operate, the experiment identified several features that would be needed for an instrument to operate in the field. The primary limitations of the preliminary field configuration were: (1) difficulty in aligning the scattered light receiver; and (2) maintaining the receiver alignment. The other features were necessary to make the operation of the instrument less tedious.

Following the August 1987 CFFF experiment, it was decided that by using optical fibers the electro-optical system could be configured into three modules: (1) the laser, color separating optics and optical fiber input coupler optics; (2) the transmission optics used beam forming and focusing; and (3) the scattered light receiver optics and detectors. The laser beams would be transmitted from the laser module to the transmission optics by single mode polarization maintaining optical fibers. The advantages of this configuration are: (1) the ability to locate the argon ion laser where environmental conditions can be maintained; and (2) the relocation of components allowed a simpler mechanical support frame to be designed.

\section{Electro-optical System}

The transmission optics components are divided into two sections which are linked with optical fibers. The Lexel Model 85 argon ion laser (500 mw output) is mounted on the 24-inch $\times 55$-inch $\times 2.5$-inch aluminum optical breadboard. Its multiwavelength output is collimated (9108) then chopped with the optical chopper (Rofin Model 7510). The individual colors are separated using the TSI color separator (9105) which utilizes two 
dispersion prisms and dielectric coated mirrors. The blue (488 $\mathrm{nm}$ ) and the green $(514.5 \mathrm{~nm})$ beams then enter the 9159 dual beam translator followed by a 9262 dual fiber input coupler and two 20 meter single mode polarization maintaining fibers (9265-1G) are attached to the exit of the input coupler.

The laser radiation is then transmitted by the two fibers to the channel location which provides optical access to the particulate flow. The ends of the fibers are then attached to the dual fiber output coupler (9263). It is followed by another dual beam translator (9159) which allows the beam spacing to be adjusted to $50 \mathrm{~mm}$. The blue beam is displaced $25 \mathrm{~mm}$ to the transmission optical assembly's centerline (91.74 prism), directed through the polarization rotator (9102-11), and then split into two parallel beams of equal power using a 9115-1 beam splitter. The green beam is then brought up to the centerline with a $25 \mathrm{~mm}$ displacing prism (9174) and a 9113-13 beam displacer is used to space the blue beams at $13 \mathrm{~mm}$. The blue beams which lie in a horizontal plane are directed into the $3.75 \mathrm{x}$ beam expander (9189-A) while the green beam passes through holes drilled in the center of the beam expander's lenses and is not expanded. A beam displacing prism (9174) then offsets the green beam at $25 \mathrm{~mm}$ below the centerline. A focusing lens with a clear aperture of $150 \mathrm{~mm}$ and $762 \mathrm{~mm}$ FL (9169-750) is then used to cross and focus the two blue and the single green beams.

The receive optics consist of collecting and focusing lenses with larger aperture and longer focal length. A single mask with a $2 \mathrm{~cm}$ square aperture located with its upper side along the horizontal plane that contains the blue beams is used to define the angles for the scattered light which is collected. The mask is attached to the front of a second $762 \mathrm{~mm}$ FL lens (9169-750) and is used to collimate the scattered light that is then focused by a $9169-450$ lens ( $480 \mathrm{~mm}$ FL) onto a 200 micron pinhole used as a spatial filter. The $150 \mathrm{~mm}$ clear aperture of these two lenses allows the transmission beams to be used for aligning the receiver's field of view. Two right angle prisms fold the optical axis back into the dichroic mirror assembly (9145) which is placed with its axis offset four inches from the centerline of the collection lens. A $300 \mathrm{~mm}$ FL lens (Melles Griot Model 01LAO256) is mounted in the entrance of the color separator assembly and is used to collimate the light passed to the dichroic mirror. The separated blue and green light exits the color separator and enters two PMT optics modules (9140) which contain laser line interference filters for the 
respective colors. The scattered light is then projected onto the photocathodes of the PMT assemblies (9162).

\section{Mechanical Support Frame}

The mechanical support frame was redesigned to meet the requirements of field measurements--easier alignment and maintaining the alignment under conditions which would be encountered in the field. It was also decided that the instrument assembly should not require more than two people. Since it was anticipated that measurements were to be performed on an elevated platform with a metal grating floor, the instrument should allow for disassembly into pieces weighing less than $100 \mathrm{lbs}$ each. To allow alignment of the optical receiver axis onto the transmission optics axis, manipulator screws should provide the required adjustments.

The support frame consists of a 6-inch $\times$ 6-inch $\times 1$ /4-inch $\times 122$-inch long aluminum $\mathrm{H}$-beam with $3 / 16$-inch flat plate reinforcements welded between the webs. This was used as a connecting member between the transmission optics assembly and the receiving optics assembly. This connecting beam is supported from cantilevered arms which rest on three conventional optical table air spring supports (Newport Research Corp. Model No. XL-A). This serves to isolate the instrument from vibrations and impacts which could be transmitted from the platform. Adjustable wooden stands were fabricated to allow matching of the instrument height to the height of the optical access windows on the sides of the flow channel. This is provided by sliding the hollow base of the air spring supports over the wooden stands until the approximate desired height is reached. Wood screws are then screwed into all four legs of each wooden stand and are used as stops which support the air legs. Further refinement of instrument height can be achieved by adjusting leveling valves which control the inflation pressure in the air spring supports. The optical table supports also incorporate a wire cable pendulum mechanism to provide isolation and damping from external horizontal disturbances. The connecting member is positioned perpendicular to the flow channel running directly under its lower wall. Spacers of appropriate height are bolted to the top of the beam and the optical assemblies are bolted to their top plates. On the transmission optics side, a 48 -inch long dovetail rail (Oriel Corp. Model No. 11532) is bolted to the top plates of the two welded aluminum spacers. The receiving optics and its positioner mechanism are mounted on top of spacers bolted to the opposite end of the connecting 
member. Sheet metal covers protect the optical assemblies from the environment.

The positioner base for the receiver optics provides five degrees of freedom 'which allows the optical axis of the receiver to be aligned collinear with the transmission optics axis. Two parallel horizontal shafts supported in linear bearings allow the base to move $1 / 2$ inch horizontally perpendicular to the optic axis and allow the receiver to tilt two degrees. Two vertical shafts provide similar freedom of movement for vertical and yaw adjustments. The two parallel shafts beside the receiver allow the positioner base to be moved along the optical axis for 1.5 inches.

\section{Signal Processor}

A new signal processor was designed incorporating many of the circuits developed for the prototype unit. The prototype unit constructed using wire wrap and point to point wiring was not sufficiently rugged for field measurements. Furthermore, it was designed for the particle velocity range encountered on the DIAL combustion test channel and could not accommodate other velocity ranges which generated ripple frequencies outside the passband of the ripple/pedestal separation filters. The prototype signal processor had circuits which were duplicated unnecessarily during its development and its construction did not adequately allow for maintenance. The new processor was constructed in two modules which plug into the Tektronix TM 5006 modular instrument mainframe: (1) a preprocessor which contains high pass and low pass filter banks for separating the ripple and pedestal signals and DC baseline restoration circuits for the SANFS and pedestal signals; and (2) a second module occupies two slots of the mainframe and contains a velocimeter circuit and three channels of logarithmic amplifiers followed by peak detectors.

The ripple logarithmic amplifier is implemented using six stages of Plessey SL531C limiting amplifiers. This circuit is AC coupled and is capable of processing ripple signal with $70 \mathrm{~dB}$ dynamic range and frequencies of up to $250 \mathrm{Mhz}$. It is followed by a diode rectifier and lowpass filter bank to obtain a pulse whose amplitude is proportional to the ripple signal. The unrectified output of the ripple log amplifier is routed to a counting and timing circuit (velocimeter) to determine the ripple frequency. A transit time velocimeter is also implemented and determines velocity from the pulse width of the SANFS and pedestal signals. 
The SANFS and pedestal log amplifiers are identical units which are DC coupled and implemented with three parallel $30 \mathrm{~dB}$ differential amplifiers (Texas Instruments TL441). This configuration has a bandwidth from $\mathrm{DC}$ to $10 \mathrm{Mhz}$ and achieves a dynamic range of $70 \mathrm{~dB}$. The highest gain amplifier stage incorporates a DC baseline restoration loop and a limiter amplifier utilizing RCA CA3046 transistor arrays. By using this limiter and other high speed Shottky diode clamps, all amplifiers operate within their active regions and excessive recovery times due to overdrive conditions are prevented.

The three peak detector modules are identical and of a two stage design. The first stage uses a high speed sample and hold amplifier (Harris HA5330) and a high speed comparator (Precision Monolithics PMI CMP-05) to determine and hold the peak of each pulse. This peak value is transferred to a second stage sample and hold (Harris HA2425) and the first stage is reset and released to track the input. A data available strobe is generated at this time to signal the digitizer. After a delay of 40 microseconds to allow for A/D conversion the second stage sample and hold is placed in track mode.

The main signal processor module containing the three log amplifier and peak detector channels is implemented on seven small printed circuit boards which plug into a larger bus board that contains the sampling and timing logic circuit. The ripple log amplifier piggybacks on the top of the velocimeter board and the pedestal and SANFS log amplifiers are on individual boards as are the three peak detectors. Two other boards are used to route signals and power from the backplane connectors of the TM 5006 mainframe.

The original PMT high voltage power supplies were replaced with a dual power supply from Pacific Instruments (Model No. 229). The original supplies incorporated a anode current limiting feature which cut in gradually. This feature and their drift were incompatible with the requirement to make absolute intensity measurements.

\section{Data Acquisition Computer}

The original S-100 based Motorola MC68000 microcomputer was replaced with an IBM AT compatible computer. The original computer had a Forth language operating system which did not support floating point arithmetic. In addition the rapid standardization of the industry to 
the PC bus made inexpensive and high performance hardware available. Application software and development tools were also readily available for IBM PC compatible systems, whereas little was available for the S-100 system.

A $12 \mathrm{Mhz}$ AT compatible computer with 640 kilobytes of RAM and an EGA color display (DELL 286) was procured in 1988 and conversion of the data acquisition software was begun. A 12 bit general purpose analog to digital (A/D) convertor with an 8 differential channel multiplexer, DMA transfer capability, and a throughput of 27,000 samples per second was obtained.

The data acquisition and instrument control interface was first converted using interpreted BASIC language. Since the digitized data was acquired using the DMA mode of the A/D interface, the resulting slow speed of execution was not a problem. A later version with a menu interface was later written in $C$ language with the count duration timer portion written in assembly language. The data analysis routines were developed in GW-BASIC and Microsoft QuickBasic. On-line analysis routines were later incorporated into the instrument control program written in $C$ language. 


\section{CURRENT STATUS}

The PSD instrument has been developed to a state in which it is operational but further development of the prototype is necessary. A continuous effort has been expended to achieve an instrument which is more flexible and can be utilized to perform measurements under real world industrial conditions. The instrument has been successfully utilized in situations where the number density and flow are quasi-steady. Many industrial applications satisfy this requirement or process conditions can be limited in a manner that is favorable for the instrument. Unfortunately, the application to particulate emissions from the CFFF was one situation where flow conditions fluctuated in a rapid manner during the time period required to accumulate a count histogram of sufficient size to be useful. Count histograms acquired under these conditions included particles which were incorrectly sized. Particles were counted as smaller (larger) particles if the effective illumination intensity was decreased (increased) by factors which affected beam attenuation. A scheme to correct groups of particles counted within a DMA buffer collection cycle was attempted. This scheme was not successful since the threshold for counting was not adjusted to account for changes in beam attenuation. Fixed thresholds resulted in under counting in bins for smaller particles and no way to determine the start of bins containing valid counts.

The results of measurements made at the CFFF facility during quasisteady conditions are shown in Appendices A through C. The three measurements were made for different facility operating conditions and are plotted together in Appendix D. The high number densities encountered limited the operation of the instrument to the ripple deconvolution mode which has the smallest sample volume.

In the development of the signal processor, recent improvements in electronics technology were very helpful in overcoming obstacles. The state-of-the-art of high speed logarithmic amplifiers was greatly advanced with the introduction of the Analog Devices AD640 integrated circuit, a 50 $\mathrm{dB}, 120 \mathrm{Mhz}$ demodulating log amplifier and detector. Two of these could be cascaded to fulfill the requirements for ripple signal processing which previously required six or more separate active components. It was also used for processing pedestal and SANFS pulses eliminating the tedious alignment required for the circuits fabricated using the TL441. Advances in operational amplifier technology resulted in a two stage peak detector of classical design that was capable of capturing pulses as narrow as $200 \mathrm{nsec}$. 
The AD843 amplifier fabricated using a complementary bipolar process achieved the high slew rate yet has the low input current required by the first stage of the circuit.

Difficulties in achieving two blue beams with stable power output stimulated ideas which resulted in a simpler design for the transmission optics system. Although it is likely that separate fibers for each blue beam would have eliminated the instability problems, a new configuration without fibers was fabricated. This configuration allowed the elimination of the polarization rotators and several of the beam displacing prisms used in the original nonfiber system. The laser was suspended under the connecting member of the support frame and a rail extension provided support for the collimator, the pair of color dispersing prisms, and a turning mirror. Two final turning mirrors were used to direct the beams into the beam splitter and the beam expander as was done in the two previous configurations.

There are several areas where further development is needed. As mentioned previously, unsteady or gusting flow conditions cause problems that may possibly be overcome with an automatic gain compensation system. It is also desirable to have banks of ripple/pedestal separation filters which can be computer controlled with sophisticated software to track changes in flow velocity. Optical assemblies similar to the fiber based probes now available for laser Doppler velocimeters could be used to miniaturize the optical system for more demanding applications. A pulse height analyzer which plugs into the bus of a PC-AT compatible computer could be used to simultaneously acquire multiple histograms as would be required for making simultaneous measurements using two or more instrument modes to cover a wider range of particle diameters and concentrations. 


\section{ACKNOWLEDGMENTS}

Many individuals contributed to this development effort which extended over a period of several years, and the authors would like to acknowledge the efforts of these colleagues.

The original investigator, Dr. James D. Gassaway, who started the development of this instrument, retired in 1991 and during many occasions since has discussed different aspects of the instrument. The first author is greatly indebted to him for his assistance and guidance both during his tenure on this project and also following his retirement. Dr. Gassaway was responsible for conceiving and developing many of the novel ideas which led to this implementation. His experience and expertise in the area of electronics design is an area where he made particularly important contributions. He developed the high frequency logarithmic amplifiers without which this design approach would have been impossible. In addition, Dr. Gassaway authored previous documents from which much of the content for the technical approach and system description sections was taken.

Dr. Thomas Philip and Mr. Richard Benton were responsible for guiding the development of the software for acquisition of data. Mr. John Etheridge made contributions to the data analysis programs, modeling of the SANFS response, and also to the electronics development. Dr. John Luthe obtained, modified and maintained the Mie code used for calculating the instrument's response characteristics. He also performed calculations for new mask configurations when the evolving instrument design dictated.

The first author's appreciation also extends to the support staff of technicians, machinists and shop personnel who were responsible for building much of the instrument. Mr. Edward Traylor is especially recognized for designing and constructing many of the later circuit boards for the signal processor. 


\section{REFERENCES}

1. Self, S.A. 1980. Particle measurements in high temperature flows. Presented at the National Science Foundation Workshop on Thermal Diagnostics for High Temperature Flows, Sept. 16-17, Mississippi State University. R.E. Powe and H.W. Coleman, eds. NSF Grant No. CME-7918512.

2. Anderson Samplers Inc., Flow Sensor Division. Mark IV product and specification literature. Atlanta, GA.

3. Hirleman, E.D. 1980. Laser-based single particle counters for in situ particulate diagnostics. Opt. Eng. 19:6:854-860.

4. Holve, D.J.; Tichenor, D.; Wang, J.C.F. 1981. Design criteria and recent developments of optical single particle counters for fossil fuel systems. Opt. Eng. 20:4:529-539.

5. van de Hulst, H.C. 1981. Light scattering by small particles. New York: Dover Publications Inc. (John Wiley \& Sons, Inc., New York, 1957).

6. Kerker, M. 1969. The scattering of light and other electromagnetic radiation. Academic Press Inc.

7. Bohren, C.F. and Huffman, D.R. 1983.Absorption and scattering of light by small particles. New York: Wiley-Interscience.

8. Wiscombe, W.J. 1980. Improved Mie scattering algorithms. Appl. Opt. 19:9:1505-1509.

9. Dave, J.V. 1968. Subroutines for computing the parameters of the electromagnetic radiation scattered by a sphere. Palo Alto, CA: Palo Alto Scientific Center. IBM Technical Report 320-3237.

10. Farmer, W.M.; Harwell, K.E.; Hornkohl, J.O.; and Schwartz, F.A. 1979. Particle sizing interferometer measurements in rocket exhaust. In Proceedings of the Third International Workshop on Laser Velocimetry, Purdue University, July 11-13, 1978, eds. H.D. Thompson and W.H. Stevenson, pp. 518-528. Hemisphere Publishing. 
11. van Buijtenen, C.J.P. and Oeseburg, F. 1974. Comparison of "light scattering diameter" based on forward scattering measurements and aerodynamic diameter of aerosol particles. Atmos. Environ. 8:9:885896.

12. Hirleman, E.D. 1977. Optical technique for particulate characterization in combustion environments: the multiple ratio single particle counter. Purdue University: PHD Thesis.

13. Hirleman; E.D.; Wittig, S.L.K.; Christiansen, J.V. 1976. Development and application of an optical exhaust gas analyzer. Technical University of Denmark, Laboratoriet for Energiteknik, Report RE 76-4.

14. Brayton, D.B. 1974. Small particle signal characteristics of a dual-scatter laser velocimeter. Appl. Opt. 13:10:2346-2351.

15. Roberds, D.W. 1975. Electronic instrumentation for interferometric particle sizing. University of Tennessee: PHD Thesis.

16. Roberds, D.W. 1977. Particle sizing using laser interferometry. App. Opt. 16:7:861-1868.

17. Bachalo, W.D. 1979. On-line particle diagnostics systems for application in hostile environments. In Proceedings of the Third International Workshop on Laser Velocimetry, Purdue University, July 11-13, 1978, eds. H.D. Thompson and W.H. Stevenson, pp. 506-516. Hemisphere Publishing.

18. Gassaway, J.D. and Stapp, R.W. 1986. A laser based instrument for measurement of particle size distributions. In Proceedings of the 24th Symposium on Engineering Aspects of Magnetohydrodynamics, Butte, Montana, Mountain States Energy, June 24-27, pp. 229-239.

19. Hess, C.F. and Espinosa, V.E. 1984. Spray characterization with a nonintrusive technique using absolute scattered light. Opt. Eng. 23:5: 604-609.

20. Hess, C.F. 1984. Nonintrusive optical single-particle counter for measuring the size and velocity of droplets in a spray. Appl. Opt. 23:23:1. 
21. Fincke, J.R.; Swank, W.D.; and Jeffery, C.L. 1990. Simultaneous measurement of particle size, velocity and temperature in thermal plasmas. IEEE Transactions on Plasma Science, 18:6:948-957.

22. Wang, C.F. and Tichenor, D. 1979. Particulate size measurements using light scattering techniques. Presented at the 1979 Symposium on Instrumentation and Control for Fossil Energy Processes, Denver, Colorado, August 20-22.

23. Bachalo,W.D.; Hess, C.F.; and Hartwell, C.A. 1979. An instrument for spray droplet size and velocity measurements. Presented at the Winter Annual Meeting of the American Society of Mechanical Engineers (Gas Turbine Division). New York. ASME Paper No. 79-WA/GT-13.

24. Finke, J.R.; Jeffery, C.L.; and Englert, S.B. 1988. In-flight measurement of particle size and temperature. J. Phys. E: Scientific Instruments. 21: 67-370.

25. Holve, D. and Self, S.A. 1979. Optical particle sizing for in situ measurements: parts 1 and 2. Appl. Opt. 18:10:1632-1652.

26. Holve, D.J. and Annen, K.D. 1984. Optical particle counting, sizing, and velocimetry using intensity deconvolution. Opt. Eng. 23: 5:591-603.

27. Holve, D.J. and Davis, G.W. 1985. Sample volume and alignment analysis for an optical particle counter sizer, and other applications. App. Opt. 24:7:998-1005.

28. TSI Inc. 1979. Laser velocimetry systems. St.Paul, MN.

29. TSI Inc. 1980. System 9100-7: laser Doppler velocimeter instruction manual. St.Paul, MN.

30. Luthe, J.C. 1991. Mie scattering calculations for PSD instrument. Diagnostic Instrumentation and Analysis Laboratory: Mississippi State University. Internal Report.

31. Siegman, A.E. 1986. Lasers. Mill Valley, CA: University Science Books. 


\section{APPENDICES}

15601-TR-13-PSD-6-94 


\section{APPENDIX A}

PSD Measurement at CFFF ESP Exit Duct: Coal Combustion and No $\mathrm{K}_{2}$ Seed Injection, ESP Flow@ $6000 \mathrm{cfm}$ 


\section{UTSI $\backslash L M F 5 F \backslash P S 081392 \backslash R D M .100$}

Thu Aug 13 13:34:22 1992

$\begin{array}{ll}\text { accumulated time } & =8.094177 \text { seconds } \\ \text { begining beam power } & =7.782909 \\ \text { ending beam power } & =7.640849 \\ \text { ADC gain code } & =2 \\ \text { Flow velocity } & =18.000000 \\ \text { Blue PMT } & =500.000000 \\ \text { Green PMT } & =500.000000 \\ \text { Total count } & =30000 \\ \text { Maximum count } & =4883 \\ & \\ \text { beam } & =7.711879 \\ \text { d32 } & =2.396148\end{array}$

RipTH=10mv...RipFreq=1.6Mhz...HP=LP=1Mhz...ESP Fields off...fl ow $=6000 \mathrm{cfm}$...

RDM mode data...ET's RipLogAmp \& PeakDetector...488 laser Int filter... Coal only!!!...step "6"

BIN count list: $>>>>$

BIN No. DIAMETER COUNT DENSITY

$\begin{array}{llll}0 & & 0 & \\ 1 & & 0 & \\ 2 & & 156 & \\ 3 & & 4883 & \\ 4 & & 4505 & \\ 5 & 2.13576 & 3300 & 13600.63 \\ 6 & 2.189853 & 2558 & 3651.353 \\ 7 & 2.244557 & 1983 & 1267.098 \\ 8 & 2.304969 & 1644 & 444.223 \\ 9 & 2.365381 & 1435 & 176.2665 \\ 10 & 2.425793 & 1240 & 87.26896 \\ 11 & 2.489995 & 1060 & 81.33623 \\ 12 & 2.557679 & 933 & 116.0099 \\ 13 & 2.625362 & 891 & 170.3656 \\ 14 & 2.693045 & 779 & 222.9184\end{array}$

15601-TR-13-PSD-6-94 


\begin{tabular}{|c|c|c|c|}
\hline 15 & 2.761528 & 645 & 260.2587 \\
\hline 16 & 2.837546 & 558 & 255.4849 \\
\hline 17 & 2.913563 & 457 & 260.9079 \\
\hline 18 & 2.989581 & 446 & 252.3602 \\
\hline 19 & 3.071443 & 382 & 218.1213 \\
\hline 20 & 3.157192 & 339 & 186.3949 \\
\hline 21 & 3.242941 & 290 & 162.9835 \\
\hline 22 & 3.32869 & 259 & 138.8799 \\
\hline 23 & 3.417896 & 177 & 111.5325 \\
\hline 24 & 3.515044 & 174 & 84.35055 \\
\hline 25 & 3.612193 & 145 & 68.57904 \\
\hline 26 & 3.709342 & 141 & 55.24771 \\
\hline 27 & 3.817774 & 124 & 39.59524 \\
\hline 28 & 3.92695 & 100 & 31.29463 \\
\hline 29 & 4.036125 & 69 & 24.82581 \\
\hline 30 & 4.156028 & 75 & 17.89857 \\
\hline 31 & 4.281584 & 54 & 13.51955 \\
\hline 32 & 4.40714 & 48 & 10.71143 \\
\hline 33 & 4.532696 & 28 & 8.489881 \\
\hline 34 & 4.672484 & 25 & 6.056751 \\
\hline 35 & 4.818493 & .15 & 4.622869 \\
\hline 36 & 4.964502 & 21 & 3.691269 \\
\hline 37 & 5.128654 & 13 & 2.631123 \\
\hline 38 & 5.301519 & 13 & 2.008975 \\
\hline 39 & 5.474383 & 7 & 1.616727 \\
\hline 40 & 5.653056 & 10 & 1.262785 \\
\hline 41 & 5.868042 & 5 & .8463938 \\
\hline 42 & 6.083026 & 4 & .6820669 \\
\hline 43 & & 1 & \\
\hline 44 & & 1 & \\
\hline 45 & & 3 & \\
\hline 46 & & 2 & \\
\hline 47 & & 0 & \\
\hline 48 & & 1 & \\
\hline $\begin{array}{l}49 \\
50\end{array}$ & & $\begin{array}{l}0 \\
1\end{array}$ & \\
\hline 51 & & 0 & \\
\hline 52 & & 0 & \\
\hline 53 & & 0 & \\
\hline 54 & & 0 & \\
\hline & & 0 & \\
\hline
\end{tabular}


58

59

60

61

62

63

0
0
0
0
0
0




\begin{abstract}
APPENDIX B
PSD Measurement at CFFF ESP Exit Duct: Coal Combustion and Step $6 \mathrm{~K}_{2}$ Seed Injection, ESP Flow@9000 cfm
\end{abstract}




\section{UTSI \LMF5F\PS081392\RDM.112}

Thu Aug 13 16:09:48 1992

$$
\begin{array}{ll}
\text { accumulated time } & =34.363575 \text { seconds } \\
\text { begining beam power } & =9.743539 \\
\text { ending beam power } & =8.474401 \\
\text { ADC gain code } & =2 \\
\text { Flow velocity } & =17.000000 \\
\text { Blue PMT } & =550.000000 \\
\text { Green PMT } & =550.000000 \\
\text { Total count } & =30000 \\
\text { Maximum count } & =4031 \\
& \\
\text { beam } & =9.108971 \\
\text { d32 } & =2.198673
\end{array}
$$

th $=10 \mathrm{mv}$ esp flow erratic about 9000

BIN count list: $\gg>>>$

BIN No. DIAMETER COUNT DENSITY

$\begin{array}{llll}0 & & 0 & \\ 1 & & 0 & \\ 2 & & 183 & \\ 3 & & 4031 & \\ 4 & & 3459 & \\ 5 & 1.691022 & 2695 & 685.7239 \\ 6 & 1.73511 & 2122 & 640.5077 \\ 7 & 1.779198 & 1816 & 512.3732 \\ 8 & 1.823648 & 1569 & 385.2062 \\ 9 & 1.872188 & 1342 & 264.7111 \\ 10 & 1.920728 & 1200 & 200.1487 \\ 11 & 1.969268 & 1082 & 153.6175 \\ 12 & 2.020387 & 1011 & 113.9918 \\ 13 & 2.07448 & 865 & 85.81 .094 \\ 14 & 2.128573 & 795 & 69.68053 \\ 15 & 2.182666 & 745 & 57.65457 \\ 16 & 2.236759 & 685 & 48.58028 \\ 17 & 2.296942 & 614 & 37.43365\end{array}$

15601-TR-13-PSD-6-94 


$\begin{array}{llll}18 & 2.357354 & 459 & 32.49046 \\ 19 & 2.417766 & 467 & 28.73613 \\ 20 & 2.481003 & 409 & 24.61008 \\ 21 & 2.548686 & 377 & 20.86215 \\ 22 & 2.616369 & 355 & 19.12916 \\ 23 & 2.684052 & 307 & 17.69493 \\ 24 & 2.751736 & 294 & 16.48804 \\ 25 & 2.827446 & 259 & 13.81427 \\ 26 & 2.903463 & 252 & 12.95185 \\ 27 & 2.979481 & 223 & 12.23088 \\ 28 & 3.060049 & 203 & 10.92092 \\ 29 & 3.145798 & 172 & 9.719961 \\ 30 & 3.231548 & 176 & 9.211406 \\ 31 & 3.317297 & 188 & 8.725725 \\ 32 & 3.404988 & 145 & 8.073624 \\ 33 & 3.502136 & 132 & 6.886148 \\ 34 & 3.599285 & 111 & 6.494 .045 \\ 35 & 3.696434 & 145 & 6.111172 \\ 36 & 3.803268 & 99 & 5.216161 \\ 37 & 3.912443 & 70 & 4.778455 \\ 38 & 4.021619 & 91 & 4.460943 \\ 39 & 4.139346 & 74 & 3.850177 \\ 40 & 4.264902 & 88 & 3.349862 \\ 41 & 4.390458 & 67 & 3.098588 \\ 42 & 4.516014 & 65 & 2.856908 \\ 43 & 4.653085 & 73 & 2.405442 \\ 44 & 4.799094 & 55 & 2.06866 \\ 45 & 4.945103 & 52 & 1.889118 \\ 46 & 5.105686 & 58 & 1.56357 \\ 47 & 5.278551 & 39 & 1.317838 \\ 48 & 5.451416 & 51 & 1.191987 \\ 49 & 5.624492 & 32 & 1.073516 \\ 50 & 5.839477 & 48 & .7767181 \\ 51 & 6.054462 & 26 & .6960582 \\ 52 & 6.269447 & 19 & .6218066 \\ 53 & 6.539625 & 30 & .4406754 \\ 54 & 6.822468 & 17 & .3738099 \\ 55 & 7.117674 & 12 & .3171515 \\ 56 & 7.535798 & 17 & .1977003 \\ 57 & 7.963152 & 6 & .1703085 \\ 58 & & 8 & \\ & & & \\ 58 & & & \\ 53 & & & \\ 53 & & & \end{array}$

15601-TR-13-PSD-6-94 
61

62

2

63 


\section{APPENDIX C \\ PSD Measurement at CFFF ESP Exit Duct: Coal Combustion and Step $8 \mathrm{~K}_{2}$ Seed Injection, ESP Flow@ $9000 \mathrm{cfm}$}


Thu Aug 13 16:23:39 1992

$\begin{array}{ll}\text { accumulated time } & =19.767546 \text { seconds } \\ \text { begining beam power } & =8.012673 \\ \text { ending beam power } & =8.182951 \\ \text { ADC gain code } & =2 \\ \text { Flow velocity } & =17.000000 \\ \text { Blue PMT } & =550.000000 \\ \text { Green PMT } & =550.000000 \\ \text { Total count } & =30000 \\ \text { Maximum count } & =3748 \\ & \\ \text { beam } & =8.097813 \\ \text { d32 } & =2.376504\end{array}$

esp $9 \mathrm{k}-$ rip freq $2.1 \mathrm{mhz}$ step 9

BIN count list: $\gg \gg \gg$

BIN No. $\quad$ DIAMETER COUNT DENSITY

$\begin{array}{llll}0 & & 0 & \\ 1 & & 0 & \\ 2 & & 207 & \\ 3 & & 3748 & \\ 4 & & 3398 & \\ 5 & & \\ 6 & 1.746136 & 2529 & 773.2358 \\ 7 & 1.790224 & 1999 & 846.0092 \\ 8 & 1.835787 & 1723 & 698.7841 \\ 9 & 1.884327 & 1407 & 519.1055 \\ 10 & 1.932867 & 1241 & 402.0782 \\ 11 & 1.981406 & 1186 & 311.5193 \\ 12 & 2.033915 & 1038 & 225.3436 \\ 13 & 2.088008 & 971 & 173.6502 \\ 14 & 2.142101 & 873 & 140.1231 \\ 15 & 2.196194 & 793 & 115.0222 \\ 16 & 2.251638 & 657 & 93.71673 \\ 17 & 2.31205 & 666 & 73.06683 \\ & 2.372462 & 609 & 63.1012\end{array}$

15601-TR-13-PSD-6-94 


$\begin{array}{llll}18 & 2.432874 & 553 & 55.35473 \\ 19 & 2.497929 & 507 & 45.76096 \\ 20 & 2.565612 & 471 & 39.68528 \\ 21 & 2.633295 & 461 & 36.24554 \\ 22 & 2.700979 & 401 & 33.45613 \\ 23 & 2.770439 & 354 & 30.36396 \\ 24 & 2.846457 & 317 & 26.03568 \\ 25 & 2.922474 & 261 & 24.58348 \\ 26 & 2.998492 & 299 & 23.31625 \\ 27 & 3.081493 & 265 & 20.32393 \\ 28 & 3.167243 & 256 & 18.7677 \\ 29 & 3.252992 & 263 & 17.92363 \\ 30 & 3.338741 & 211 & 17.12753 \\ 31 & 3.429283 & 203 & 15.49539 \\ 32 & 3.526431 & 196 & 13.78257 \\ 33 & 3.62358 & 178 & 13.1353 \\ 34 & 3.721395 & 185 & 12.41207 \\ 35 & 3.830571 & 160 & 10.55696 \\ 36 & 3.939746 & 138 & 9.997837 \\ 37 & 4.048922 & 120 & 9.44368 \\ 38 & 4.170745 & 109 & 7.971831 \\ 39 & 4.296301 & 114 & 7.264205 \\ 40 & 4.421857 & 110 & 6.802276 \\ 41 & 4.547413 & 93 & 6.349551 \\ 42 & 4.689599 & 98 & 5.217533 \\ 43 & 4.835608 & 86 & 4.713035 \\ 44 & 4.981616 & 81 & 4.358146 \\ 45 & 5.148917 & 85 & 3.505715 \\ 46 & 5.321781 & 64 & 3.117538 \\ 47 & 5.494646 & 50 & 2.855351 \\ 48 & 5.678256 & 52 & 2.454424 \\ 49 & 5.89324 & 42 & 1.908139 \\ 50 & 6.108226 & 34 & 1.731426 \\ 51 & 6.327517 & 27 & 1.535705 \\ 52 & 6.610359 & 15 & 1.073854 \\ 53 & 6.893201 & 26 & .9657068 \\ 54 & 7.222239 & 17 & .7443622 \\ 55 & 7.640363 & 23 & .5237301 \\ 56 & & 8 & \\ 57 & & 7 & \\ 58 & & 3 & \\ & & & \\ 53 & & \end{array}$

15601-TR-13-PSD-6-94 


\section{APPENDIX D}

\section{Plot of PSD at UTSI CFFF ESP Exit Duct}




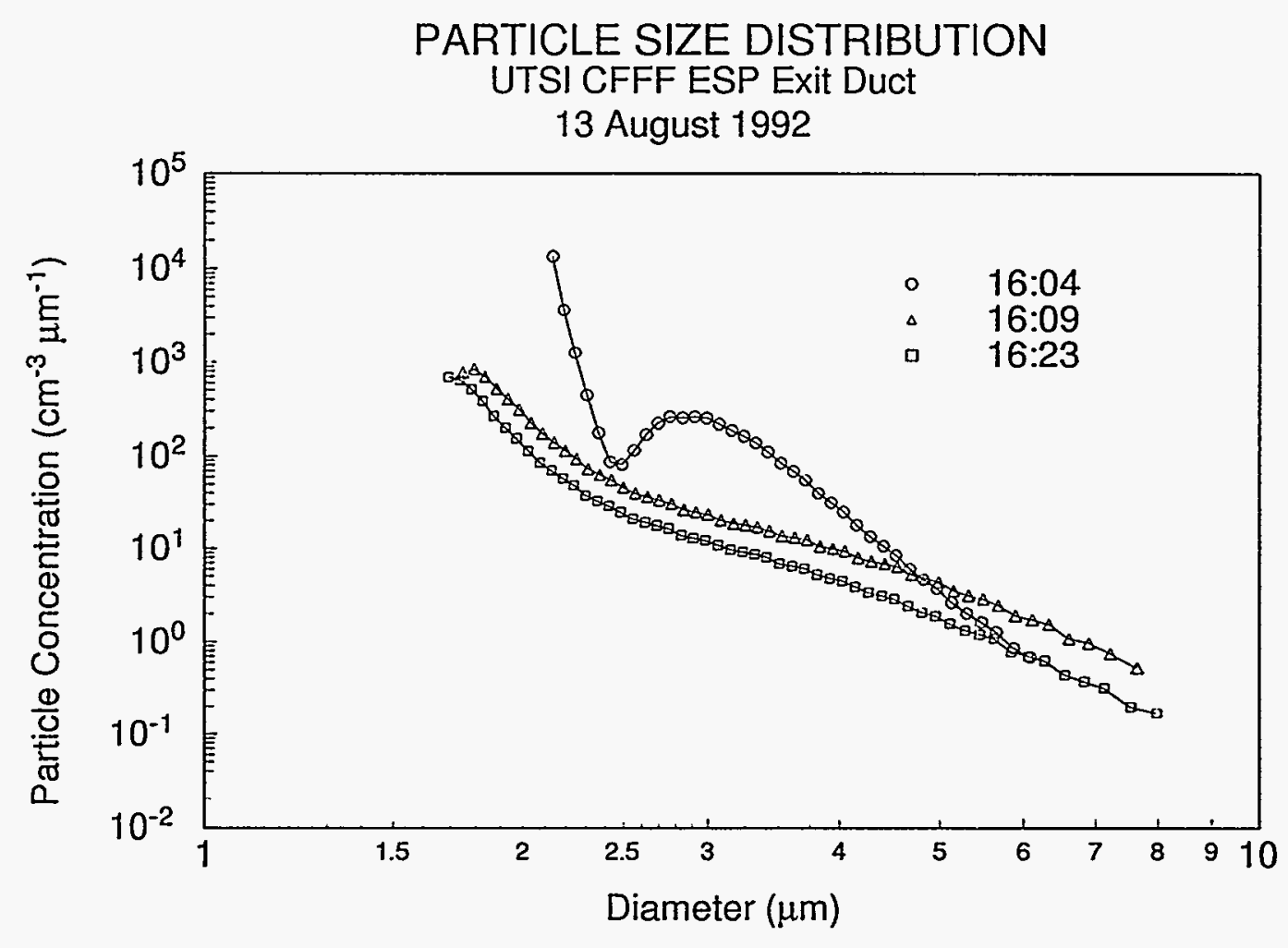

15601-TR-13-PSD-6-94 